\title{
A Rule Based Energy Management System of Experimental Battery/Supercapacitor Hybrid Energy Storage System for Electric Vehicles
}

\author{
Qiao Zhang, Weiwen Deng, Sumin Zhang, and Jian Wu \\ State Key Laboratory of Automotive Simulation and Control, Jilin University, Changchun 130022, China \\ Correspondence should be addressed to Sumin Zhang; zhangsumin@jlu.edu.cn
}

Received 21 January 2016; Revised 22 May 2016; Accepted 26 May 2016

Academic Editor: Ahmed M. Massoud

Copyright () 2016 Qiao Zhang et al. This is an open access article distributed under the Creative Commons Attribution License, which permits unrestricted use, distribution, and reproduction in any medium, provided the original work is properly cited.

In this paper, a simple and efficient rule based energy management system for battery and supercapacitor hybrid energy storage system (HESS) used in electric vehicles is presented. The objective of the proposed energy management system is to focus on exploiting the supercapacitor characteristics and on increasing the battery lifetime and system efficiency. The role of the energy management system is to yield battery reference current, which is subsequently used by the controller of the DC/DC converter. First, a current controller is designed to realize load current distribution between battery and supercapacitor. Then a voltage controller is designed to ensure the supercapacitor SOC to fluctuate within a preset reasonable variation range. Finally, a commercial experimental platform is developed to verify the proposed control strategy. In addition, the energy efficiency and the cost analysis of the hybrid system are carried out based on the experimental results to explore the most cost-effective tradeoff.

\section{Introduction}

Electric vehicles are considered as one of the most promising transportation tools for addressing issues faced by automotive industry worldwide on energy and environment [1-4]. Technologies employed for all kinds of electric vehicles are various, but their performances are largely dependent on the characteristics of adopted energy storage system (ESS) $[5,6]$. Of all the ESSs, battery is one of the most widely used in kinds of electric vehicles, which has been an emerging area for ensuring a successful application of electric vehicles. However, battery alone as a power source has yet faced some challenges for practical engineering application, such as higher energy efficiency, smaller voltage drops, larger vehicle acceleration or deceleration rates, and better uphill climbing performance. Although high power battery can be made available, it is very bulky yet cost prohibitive $[7,8]$.

A possible solution to the battery dilemma is to add onboard supercapacitor to form HESS with the purpose that battery and supercapacitor function as a complementary role based on their individual dynamic characteristics $[9,10]$.
Battery has high energy density and relatively low cost per watt-hour but low specific power and short lifetime, while supercapacitor preserves high power density and long cycle life but relatively low energy density and high cost per watthour [11-14]. Consequently, a combination of these two types of ESSs will yield an equivalent ESS with both high energy density and high power density, where energy is stored in the battery and power is supplied by the supercapacitor. In this way, sudden peak current in battery, which can be resulting in a large reduction in lifetime $[15,16]$, can be avoided effectively. Besides, electric vehicle range can also be extended because of the high utilization of the regenerative breaking [17].

In order to encourage the development of battery and supercapacitor HESS, mounting research efforts have been devoted to improving the HESS performance from both low level topology structure [11, 18-20] and high level energy management [21-28]. In the literature, there are a number of hybridization topology structures where the supercapacitor has been implemented in combination with battery systems. Based on these topology structures, various energy management control strategies for battery and supercapacitor 
HESS are also developed in the literature. These strategies can be broadly classified into rule based and optimizationbased distribution. Rule based controllers are referred to as deterministic rule, learning network, and fuzzy logical controller. In [21], an ADVISOR-based battery and supercapacitor HESS was developed; the power distribution rule between battery and supercapacitor was determined based on an experiment approach. In [22], an integrated rule based metaheuristic approach was presented, and simulation results have proved the effectiveness of this multilevel EMS fulfilling the requested performance with better source usage and much lower installed capacities. In [23], a fuzzy logical controller based on particle swarm optimization algorithm was presented to achieve optimization power flow distribution between battery and supercapacitor. Reference [24] adopted the idea of neural networks and developed an efficient energy management system for hybrid electric vehicles with closed form approaches.

Optimization-based methods consider local and global optimization problems by using past driving cycle information to determine the power distribution mode among power sources. Reference [25] formulated an optimization problem by concerning the minimization of the magnitude/fluctuation of the current flowing in and out of the battery and the energy loss of the supercapacitor. An MPC (model predictive control) controller for a hybrid batterysupercapacitor power source was proposed and experimentally verified in [26]. The designed MPC controller enables the battery to share the low frequency power components and the high frequency power components are allocated to the supercapacitor. In [27], a wavelet transform-based power management strategy was proposed, in which load power is decomposed into different frequency components to the FC (fuel cell), battery, and supercapacitor, compatible with their respective dynamic characteristics. Reference [28] adopted a first-order low-pass filter, which was designed for frequency decomposition along with analysis of components responses under real world driving cycles. These strategies would increase battery lifetime attributing to effective frequency separation consideration.

In this paper, a rule based energy management system is developed for a semiactive hybrid system. The objective of the proposed energy management system is to focus on exploiting the supercapacitor characteristics and increasing the battery lifetime and system efficiency. The main contributions of this paper are summarized as follows. First, a simple but effective rule based energy management system is developed for a semiactive hybrid system. The main role of the energy management system is to yield battery reference current according to energy levels of the power sources and load demand level. Then two classical PI control loops are proposed to adjust the load distribution between battery and supercapacitor. The described energy management system enables the battery to share low frequency and smooth load current, and the corresponding high frequency and peak current are distributed to the supercapacitor. This system prevents an overstress on the battery while maintaining a good voltage balance of the supercapacitor. This is an important advantage to ensure the vehicle starts a new cycle if high acceleration is required. Second, an experimental platform of the hybrid system is developed to verify the described energy management system using two standard drive cycles for an electric vehicle. Finally, preliminary but significant energy efficiency and the cost analysis of the hybrid system are carried out based on the experimental results to explore the most cost-effective tradeoff.

The rest of this paper is organized as follows: Section 2 describes the dynamic characteristics of the battery and supercapacitor. Section 3 analyzes the hybrid topology structure. Section 4 describes the energy management control strategy. Section 5 verifies the proposed control strategy based on a commercial experimental platform. Finally, the paper is concluded in Section 6.

\section{Characteristics of Battery and Supercapacitor as Power Sources}

Batteries used in electric vehicle usually have the characteristics of high energy density and relatively low power density. The latter is a limitation to improve vehicle dynamic performance. High power capability requires the resistance of the battery to be low. Hence, knowledge of the resistance of a battery is critical to the ability to assess its power capability. In addition, the charging and discharge internal resistances of battery are usually different, which is dependent on charging and discharge operating conditions, including amplitude and frequency of charging and discharge of battery. For lithiumion battery, the internal resistance could increase when high frequency loads are exerted. The ampere-hour capacity is affected by the discharging current rate and is modeled by the Peukert equation [13]. The charging and discharging internal resistances are nonlinear functions of current and state of charge (SOC).

Recently, another energy storage device, the supercapacitor, has attracted much interest because of its high power density $(300 \mathrm{~W} / \mathrm{kg}-5000 \mathrm{~W} / \mathrm{kg})$ and relatively low energy density. There are presently commercially available carbon/carbon supercapacitor devices (single cells and modules) from several companies, such as Maxwell, Ness, EPCOS, Nippon Chemi-Con, and Power Systems. All these companies market large devices with capacitance of 1000-5000 F. These devices are suitable for high power vehicle applications [29].

As described above, the difference between battery and supercapacitor can provide the complementary advantage to meet power and energy demand. From the perspective of power characteristics, the charging and discharging efficiency of system is usually considered as the main factor. By comparison, only one-half of the energy at the peak power from the battery is in the form of electrical energy to the load, and the other one-half is dissipated within the battery as heat in the ESR. That is to say the efficiency of batteries is around $50 \%$. For supercapacitor, the peak power is usually for a $95 \%$ efficient discharge, in which only $5 \%$ of the energy from the device is dissipated as heat in the ESR. For a corresponding high-efficiency discharge, batteries would have a much lower power capability. Furthermore, the main drawback of the batteries is a slow-charging time, limited by a charging current; in contrast, the supercapacitor may be charged in 


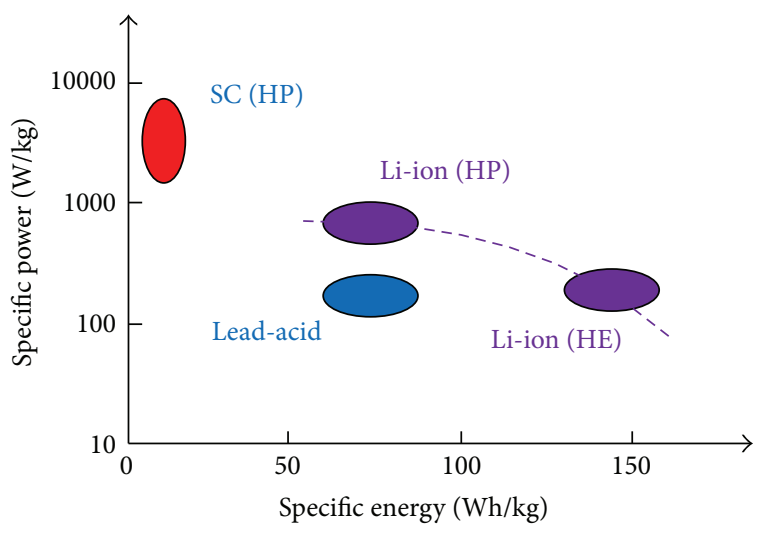

HP: high power HE: high energy

Figure 1: Comparison of battery and supercapacitor.

a short time depending on a high-charging current (power) available from the main source [30].

Figure 1 shows the comparison of battery and supercapacitor in terms of power and energy. Even though it is true that a battery has the largest energy density (meaning more energy is stored per weight than other technologies), it is important to consider the availability of that energy. This is the traditional advantage of supercapacitor. With a time constant of less than $0.1 \mathrm{~s}$, energy can be taken from a supercapacitor at a very high rate [31]. Electrochemical reactions in battery and double-layer effects in supercapacitor will yield different acceleration and deceleration transient behaviors of voltage and current, which are described as different time constants in dynamic equivalent circuit models.

\section{Hybrid Topology Structure}

Hybrid energy storage systems are formed in some typical topologies in order to manage the power flow between battery and supercapacitor, each of which has its own properties. In this section, the advantages and disadvantages of four commonly used hybrid structures for electric vehicles are described.

Figure 2 shows a passive topological structure, in which both battery and supercapacitor are directly connected in parallel. Although it is simple and easy to be realized in HESS, the power distribution is inherently limited by their internal resistance since the voltage of both battery and supercapacitor is the same [25].

Figure 3 shows one of the semiactive topological structures, in which the DC/DC converter is connected to the voltage side of the battery, and the battery voltage can be boosted up such that the battery pack can be made smaller to reduce its weight and volume. Further, with this structure, the battery voltage can be controlled more effectively [32].

Figure 4 shows another type of the semiactive topological structures, in which the voltage of supercapacitor is controlled by a bidirectional DC/DC converter, so that the supercapacitor can be boosted up to meet the driving

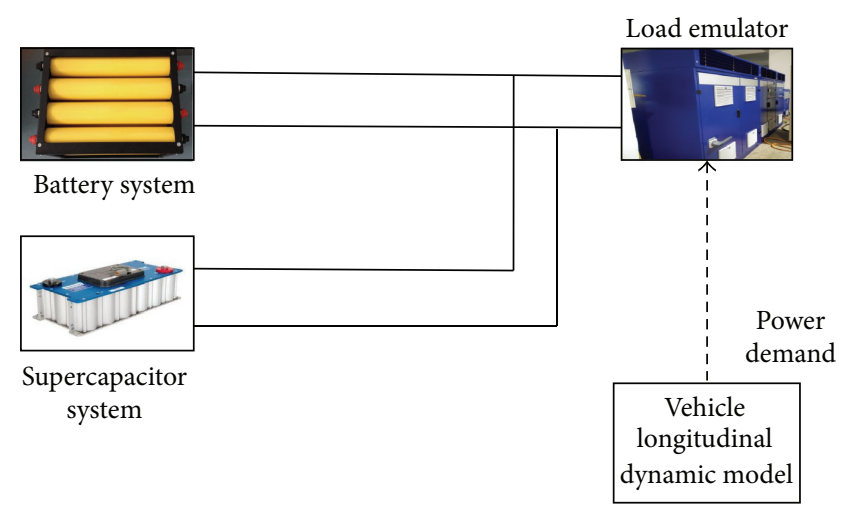

- Cable line

FIgURE 2: A passive topological structure.

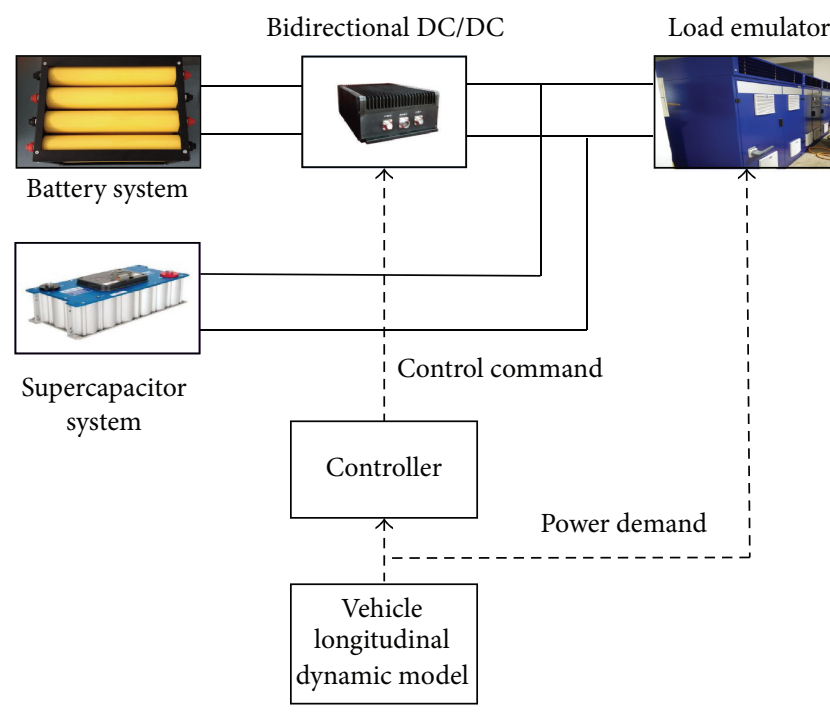

- Cable line

--- CAN line

FIgURE 3: A semiactive topological structure.

power demand for electric vehicles. Likewise, it can also be reduced to a lower level for the purpose of energy recovery via regenerative braking. This would enable supercapacitor to operate in a wider voltage range and to curb voltage fluctuation and peak current damage to battery. Even if it was not controlled by a bidirectional DC/DC converter, the battery would still work in a high effective range [11].

A fully active topological structure is shown in Figure 5. In this structure, two bidirectional DC/DC converters are used such that the hybrid power system is decoupled between battery and supercapacitor. Therefore, both power sources can be controlled via each individual DC/DC converter independently. This structure can be more flexible, stable, and efficient for voltage control and power distribution between 


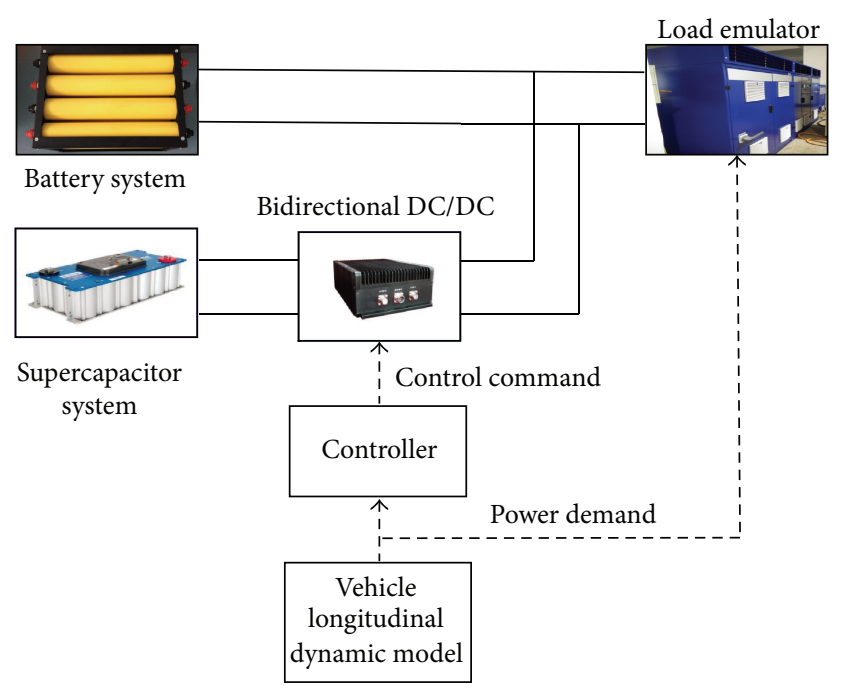

- Cable line

FIGURE 4: Another type of semiactive topological structures.

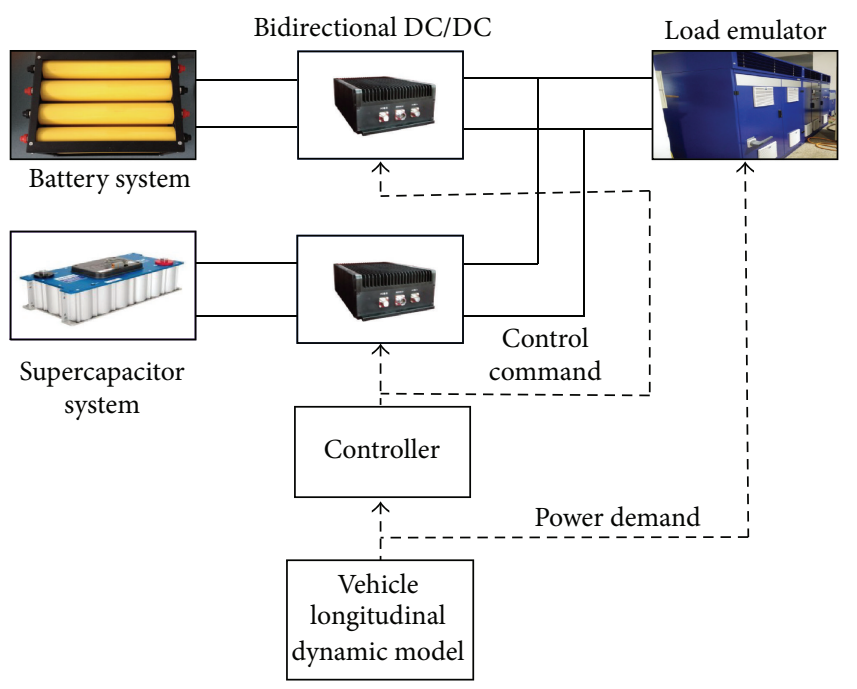

- Cable line

Figure 5: A fully active topological structure.

battery and supercapacitor. It can also reduce the size and weight of the hybrid energy storage system [19].

As a brief summary, the passive hybrid system is simple in structure and more cost-effective, but the fully active hybrid system offers the best performance. Therefore, a semiactive hybrid system is often a good tradeoff among them in terms of the performance, the structure complexity, and the costeffectiveness.

\section{Energy Management Control Strategy}

The presented energy management system control frame in this research is illustrated in Figure 6.

4.1. Energy Management System. The function of energy management system is to supply battery reference current, which is subsequently used by the controller.

The power demand calculation of hybrid system can be obtained by considering vehicle dynamics, and the total power demand consisted of rolling resistance power, aerodynamic drag power, slope resistance power, and acceleration resistance power:

$$
P_{\text {veh }}=P_{\text {roll }}+P_{\text {aer }}+P_{\text {slope }}+P_{\text {acc }}
$$

where the rolling resistance power is described as

$$
P_{\text {roll }}=\frac{u_{\mathrm{veh}}}{\eta} \frac{M g f \cos (\alpha)}{3600} .
$$

The aerodynamic drag power is described as

$$
P_{\text {aer }}=\frac{1}{\eta} \frac{C_{\text {aer }} A_{\text {aer }}}{76140} u_{\mathrm{veh}}^{3} \text {. }
$$

The slope resistance power is described as

$$
P_{\text {slope }}=\frac{u_{\mathrm{veh}}}{\eta} \frac{M g \sin (\alpha)}{3600} .
$$

The acceleration resistance power is described as

$$
P_{\mathrm{acc}}=\frac{u_{\mathrm{veh}}}{\eta} \frac{\delta M}{3600} \frac{d u_{\mathrm{veh}}}{d t} .
$$

The total current demand can be calculated as

$$
I_{\text {load }}=\frac{P_{\text {veh }}}{U_{\text {bus }}},
$$

where $U_{\text {bus }}$ is the bus voltage, $M$ is the vehicle mass, $u_{\text {veh }}$ is the vehicle velocity, $g$ is gravity constant, $f$ is the rolling resistance coefficient, $\alpha$ is the road slope angle, $C_{\text {aer }}$ is the aerodynamic drag coefficient of the vehicle, $A_{\text {aer }}$ is the frontal area of the vehicle, and $\eta$ is the drive efficiency.

State of charge (SOC) is traditionally used to indicate the residual electricity of the battery; its definition is usually written by the equation

$$
\mathrm{SOC}_{\mathrm{bat}}=\mathrm{SOC}_{0}-k_{\mathrm{ch}} \cdot k_{\mathrm{dis}} \cdot \int \varepsilon \cdot \frac{I_{\mathrm{bat}} d t}{C_{\mathrm{bat}}},
$$

where $\mathrm{SOC}_{0}$ describes the initial value of $\mathrm{SOC}_{\mathrm{bat}} ; k_{\mathrm{ch}}$ and $k_{\mathrm{dis}}$ describe the influence coefficients on the current integration from charging current $\left(I_{L}<0\right)$ and discharging current $\left(I_{L}>0\right)$, respectively; if the battery is charging, $k_{\text {dis }}=1$, and if the battery is discharging, $k_{\mathrm{ch}}=1$. $C_{\mathrm{bat}}$ describes the nominal capacity of battery; $\varepsilon$ is the coulomb efficiency (including charging efficiency $\varepsilon_{\mathrm{ch}}$ and discharging efficiency $\left.\varepsilon_{\mathrm{dis}}\right)$. 


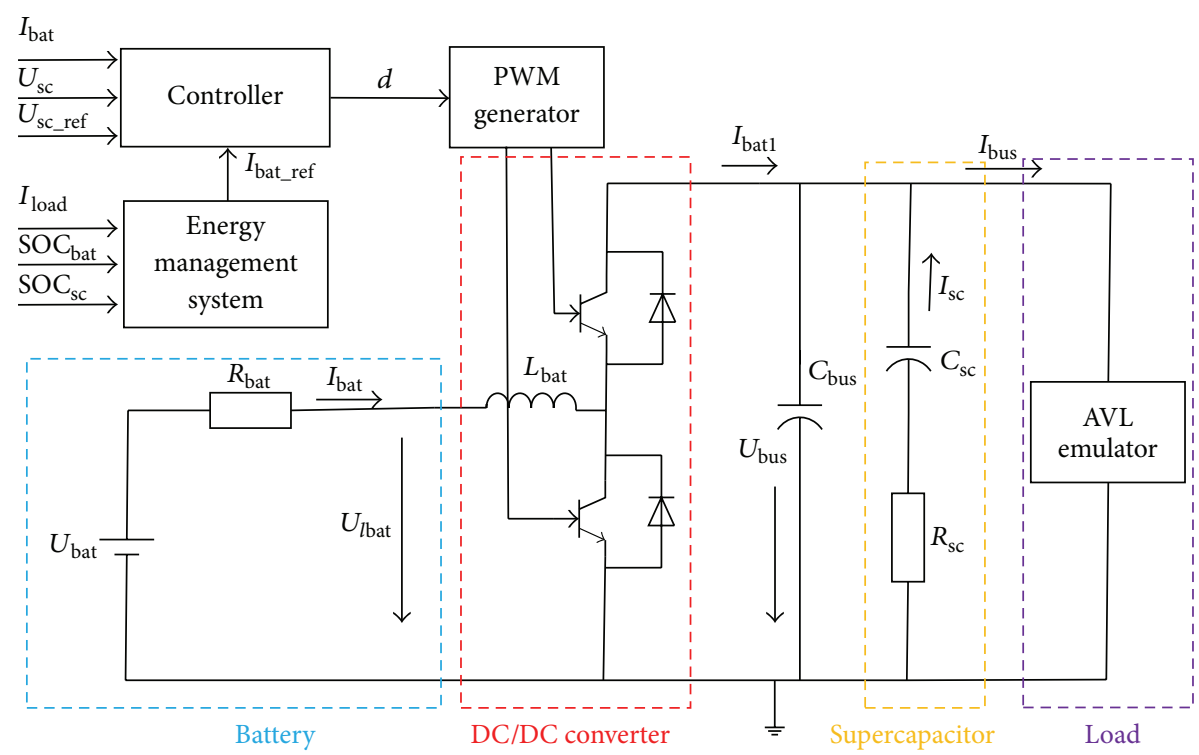

FIgURE 6: Control frame of the HESS.

In order to indicate the residual electricity of supercapacitor, the state of charge (SOC) of the supercapacitor is used to describe a percentage of the rated energy capacity, which depends on the terminal output voltage and is defined as in the equation

$$
\operatorname{SOC}_{\mathrm{SC}}=\frac{\left(U_{\mathrm{LSC}}-U_{c \min }\right)}{\left(U_{c \max }-U_{c \min }\right)},
$$

where $U_{\text {LSC }}$ is supercapacitor load voltage and $U_{c \max }$ and $U_{c m i n}$ are the maximum and minimum terminal voltage, respectively.

The proposed energy management system is a rule based and power-balancing strategy. The strategy is realized by a series of simple control logical rules. The main advantage of the proposed strategy is to protect battery from the high dynamics in current demand without overdischarging or overcharging the supercapacitor. Consequently, both battery lifetime and energy efficiency are increased.

The flowchart of DC/DC converter control mode strategy is shown in Figure 7. The control mode depends on the symbol of the load current demand. The positive load current represents the fact that the vehicle is driving. In this situation, battery or supercapacitor must supply the requirement driving current to meet vehicle driving demand. Therefore, the DC/DC converter need be switched to buck mode. However, the DC/DC control mode also depends on the charge and discharge relationships between battery and supercapacitor. Even if the load current is positive, the DC/DC converter is also switched to boost mode when the supercapacitor charges battery. In this way, the supercapacitor SOC can be adjusted to the expected variation range quickly and thus can ensure the HESS to meet the load current demand without overcharge or overdischarge of the battery. As a result, the battery operation condition can be smoothed greatly and battery lifetime is increased as well.

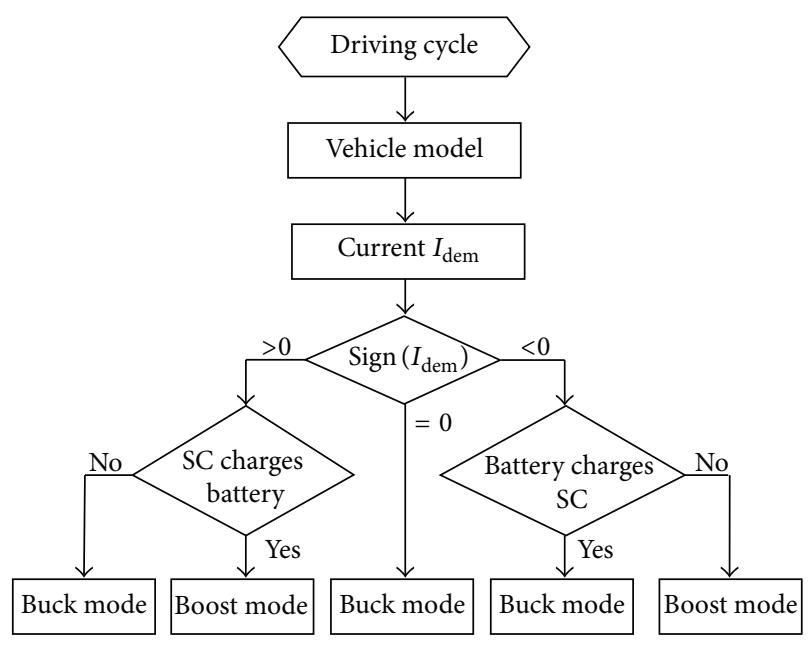

FIGURE 7: Flowchart of the DC/DC converter control mode strategy.

The flowchart of driving mode control strategy is shown in Figure 8. This decision-making flowchart considers as the first decision a comparison of the real supercapacitor SOC and the preset supercapacitor SOC variation range. If the real supercapacitor SOC is located in the preset supercapacitor SOC variation range, then the load current is distributed to supercapacitor only and the battery will not supply any load current. The purpose of this arrangement is to protect battery from the frequent charge and discharge process and increase battery lifetime. When the preset supercapacitor SOC variation range is broken, the battery is considered to balance the supercapacitor SOC or share the load current. In this situation, if the supercapacitor SOC exceeds its upper limit value, then the load current is distributed to supercapacitor only. Besides, the supercapacitor is charged by the battery. In this way, the supercapacitor SOC can be decreased to the 


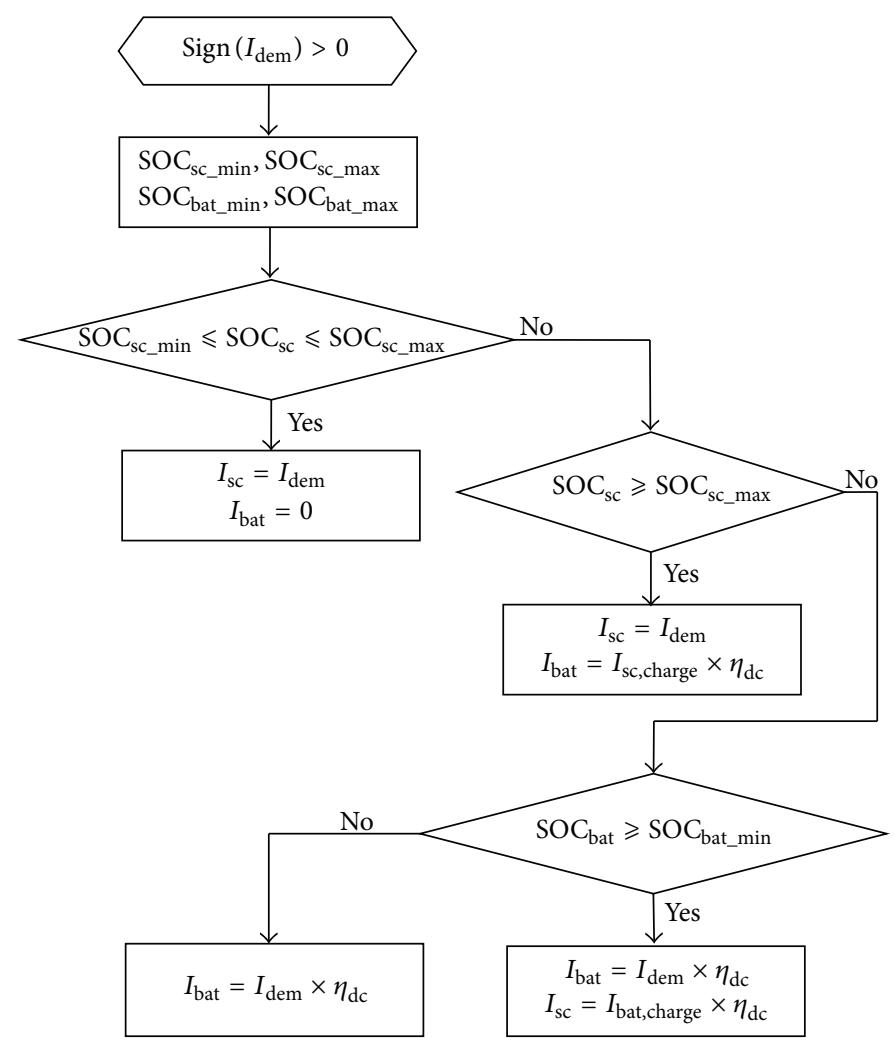

FIGURE 8: Flowchart of driving condition control mode.

preset variation range quickly and thus guarantee the supercapacitor to work within the reasonable capacity fluctuation range. If the supercapacitor SOC drops down to its lower limit value, the battery is considered to share the load current to avoid the large drop of the supercapacitor SOC. When the battery SOC is bigger than its preset minimum value, the load current is distributed to battery only. At the same time, the supercapacitor is charged by the battery. Otherwise, the supercapacitor cannot be charged by the battery. It must be noted that the described rules above mainly include five work modes for the battery and supercapacitor: the battery work only, the supercapacitor work only, the battery charges to the supercapacitor, the supercapacitor charges to the battery, and the battery and supercapacitor working together. In fact, when the supercapacitor exceeds the preset supercapacitor SOC variation range, the load current is distributed to battery and supercapacitor jointly. In this process, the charge is also carried out simultaneously.

The flowchart of idle speed mode control strategy is shown in Figure 9. Generally, the SOC of the supercapacitor is controlled within a certain reasonable fluctuation range. This is to ensure that electric vehicle is able to run even if a high acceleration or deceleration is required without overstressing the battery. Therefore, the idle speed mode control strategy is only to ensure the supercapacitor SOC to be controlled within preset fluctuation range. When the supercapacitor SOC is below the preset lower limit value, the supercapacitor is charged by the battery. On the contrary, the supercapacitor is discharged. Otherwise, no operation is carried out.
The flowchart of braking mode control strategy is shown in Figure 10. Similar to the driving mode control strategy, the battery current is firstly set to zero; this is very important to protect the battery from big current burst during the transient process. Then the only decision in this flowchart depends on the SOC of the supercapacitor and on the preset variation range. When the supercapacitor SOC is below the preset lower limit value, then the supercapacitor can absorb the current from the regenerative breaking. At the same time, the lacking energy is supplied by the battery charge. When the supercapacitor SOC exceeds the preset higher limit value, the regenerative breaking current is absorbed by battery. At the same time, the part energy is delivered to battery from the supercapacitor. Otherwise, the regenerative breaking current is absorbed by the supercapacitor only.

4.2. Controller. The input variable of controller is the battery reference current, and the output variable is the controller command. In order to realize control objective, a classical PI controller is adopted in this research. In this described configuration, the battery is connected to the DC/DC converter but the supercapacitor is directly connected to the bus without $\mathrm{DC} / \mathrm{DC}$ converter. The current relations can be written by

$$
C_{\text {bus }} \cdot \frac{d U_{\text {bus }}}{d t}=I_{\text {bat1 }}+I_{\mathrm{SC}}-I_{\text {bus }}
$$




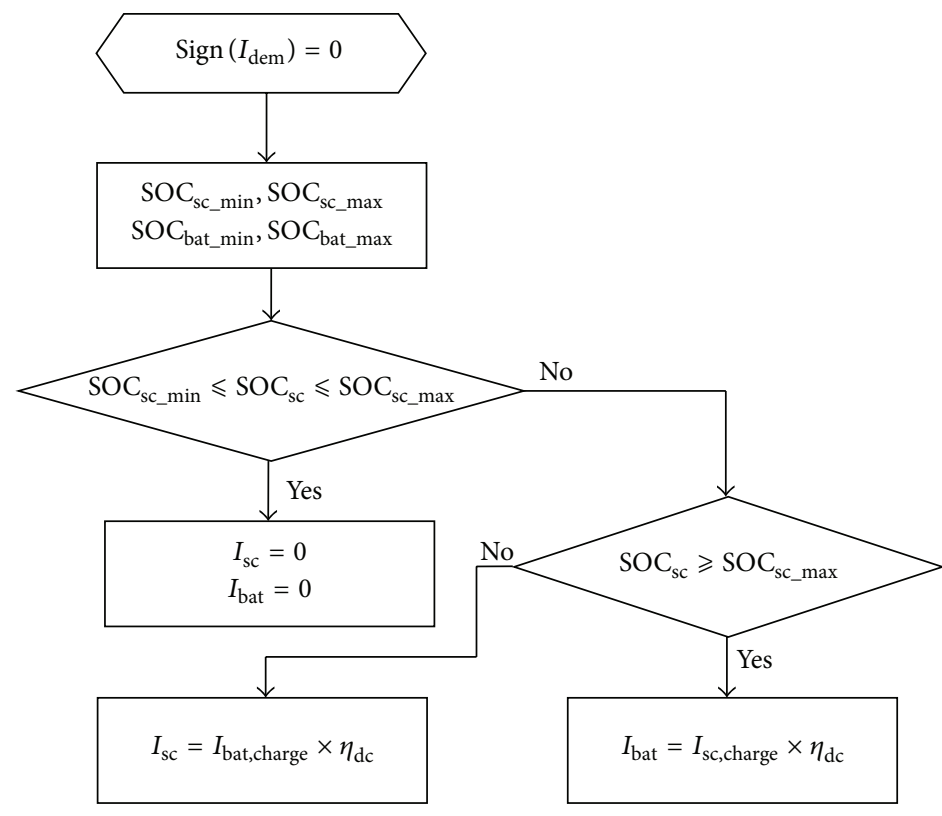

FIGURE 9: Flowchart of idle speed condition control mode.

The equivalent model of the DC/DC converter connected to the battery can be described as

$$
L_{\text {bat }} \frac{d I_{\text {bat }}}{d t}+R_{\text {bat }} I_{\text {bat }}=U_{L \text { bat }}-d \cdot U_{\text {bus }} \text {. }
$$

Equation (10) is a nonlinear first-order equation; by using the Laplace transform, we can obtain that

$$
I_{\text {bat }}(s)=\frac{U_{L b a t}(s)}{L_{\text {bat }} \cdot s+R_{\text {bat }}}-\frac{d(s) U_{\text {bus }}}{L_{\text {bat }} \cdot s+R_{\text {bat }}} .
$$

The control loop of the battery current is described in Figure 11. The input is the DC/DC converter control command; the output is the battery current. In order to balance the hybrid system without overdischarging the supercapacitor, a supercapacitor voltage compensation loop has been implemented, which is shown in Figure 12.

\section{Experimental Results and System Analysis}

5.1. Experimental Results. In order to validate the proposed energy management control strategy, a commercial experimental platform is constructed. The whole experimental platform mainly includes two parts: hardware power system and software control system, which are shown in Figures 13 and 14.

The supercapacitor pack adopted in this experimental platform is the Maxwell/BCAP3000 type, rated 3000 F, $2.7 \mathrm{~V}$ having the parameters given in Table 1 . The battery pack for the HESS is ternary lithium battery, which is considered as the next generation battery used in electric vehicle. The specific parameters of the battery pack are listed in Table 2. The presented DC/DC is a bidirectional DC/DC converter, by which both the driving current and the braking current can be controlled for the battery pack. The main parameters
TABLE 1: Parameters of the supercapacitor pack.

\begin{tabular}{lc}
\hline Items & Specifications \\
\hline Nominal voltage & $240 \mathrm{~V}$ \\
Nominal capacity & $55 \mathrm{~F}$ \\
Number of cells & 88 \\
Maximum continuous power & $30 \mathrm{~kW} / 13 \mathrm{~s}$ \\
Pack mass & $45 \mathrm{~kg} \pm 5 \%$ \\
Maximum operating temperature & $+65^{\circ} \mathrm{C}$ \\
Minimum operating temperature & $-40^{\circ} \mathrm{C}$ \\
Maximum storage temperature & $+70^{\circ} \mathrm{C}$ \\
Minimum storage temperature & $-40^{\circ} \mathrm{C}$ \\
Communication type & $\mathrm{CAN} 2.0 \mathrm{~B}, \mathrm{~J} 1939$ \\
Leakage current & $5.3 \mathrm{~mA}$ \\
Safe level & $\mathrm{IP} 65$ \\
Vibration & $\mathrm{IEC} 16750$ \\
Lifetime & $25^{\circ} \mathrm{C}, \geq 10$ years \\
Initial $48 \mathrm{~V}$ module resistance & $6.3 \mathrm{~m} \Omega$ \\
Shock & $\mathrm{SAE} \mathrm{J} 2464$ \\
\hline
\end{tabular}

of the DC/DC converter are listed in Table 3. The Electric Control Unit (ECU) is a dSPACE-based MicroAutoBox (DS 1401). Two CAN controllers in the MicroAutoBox are adopted for the load current calculation and control algorithm calculation, respectively.

The experiment was carried out to test the control strategy based on two driving cycles, that is, the USA Urban Dynamometer Driving Schedule (UDDS) and the New European Driving Cycle (NEDC). Simulation results and comparisons between the batteries only power system and the HESS system for UDDS driving cycle are shown in Figures 15-21. 


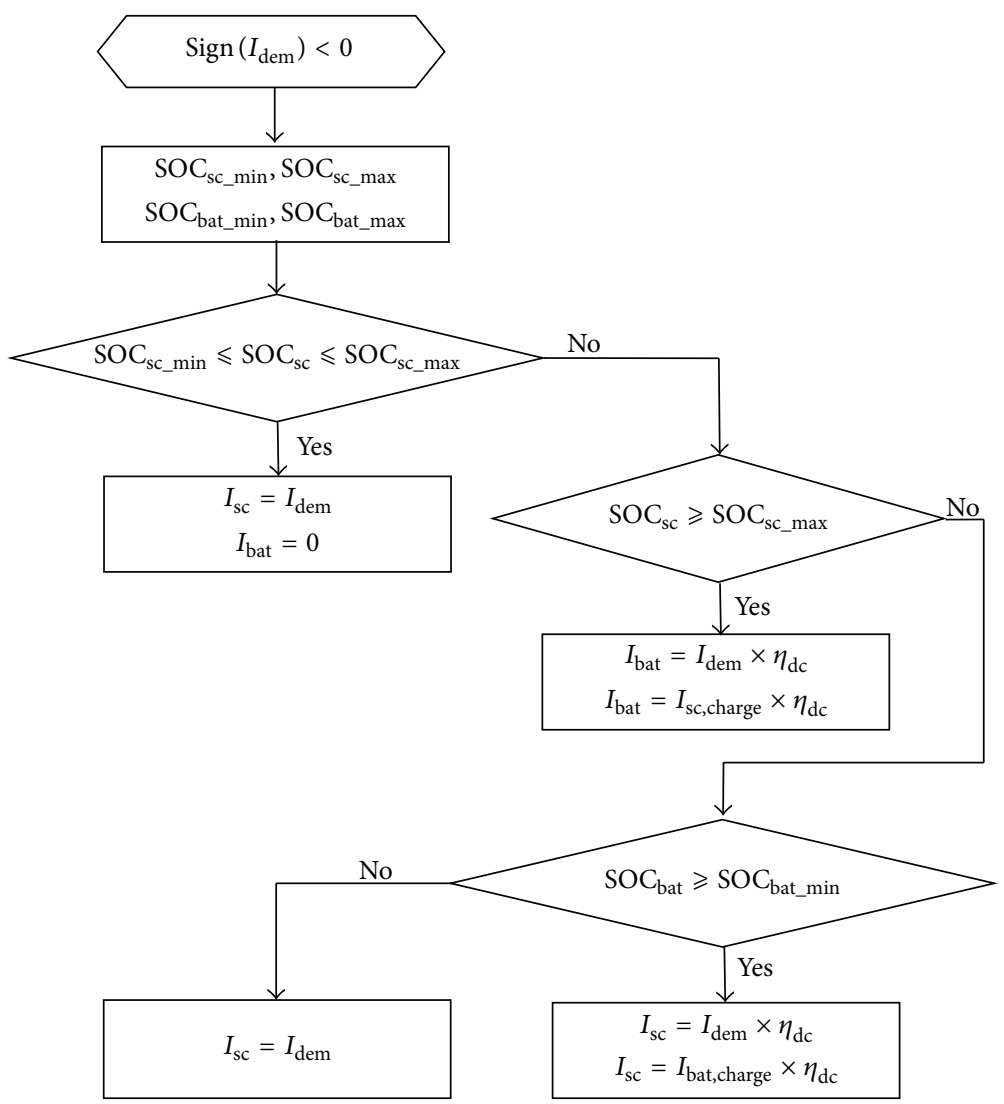

FIGURE 10: Flowchart of braking condition control mode.

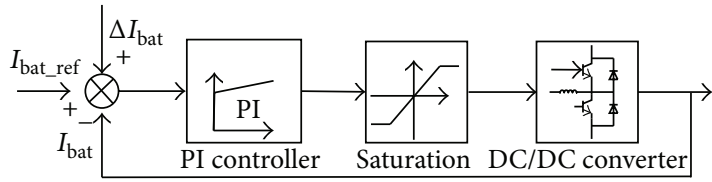

FIGURE 11: Battery current control loop.

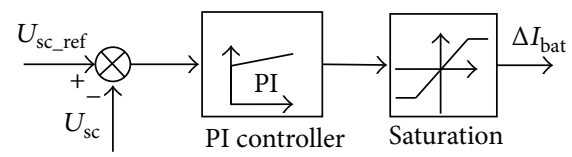

FIGURE 12: Supercapacitor voltage regulation loop.

The charging and discharging currents of battery system are compared in Figure 16. Since the supercapacitor pack can absorb the regenerative braking energy quickly and supply a burst current demand, thus the impact of big charging and discharging current on the battery pack is avoided. It can be observed that the current of battery system for the HESS is mainly maintained in range from $-20 \mathrm{~A}$ to $20 \mathrm{~A}$, which means that depth of discharge (DOD) of the battery pack is less than $0.33 \mathrm{C}$, which is beneficial to extending battery lifetime because the number of cycles to failure increases exponentially as DOD decreases.

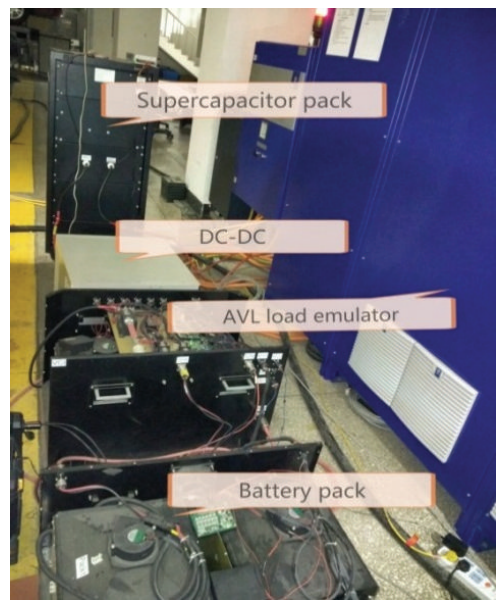

FIgURE 13: Hardware power system.

The evolutions of the battery voltage are compared in Figure 17. It can be obviously observed that large voltage drop of the HESS can be avoided compared to that of the battery only system; namely, a good voltage stabilization performance can be guaranteed for the battery system. It can be seen that the battery voltage of the HESS is maintained within the range from $279 \mathrm{~V}$ to $287 \mathrm{~V}$, and the corresponding voltage difference is $8 \mathrm{~V}$. For the battery pack with 72 series 


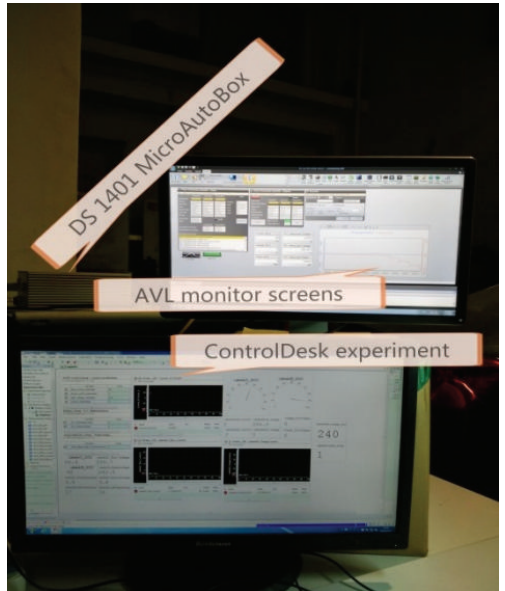

FIGURE 14: Software control system.

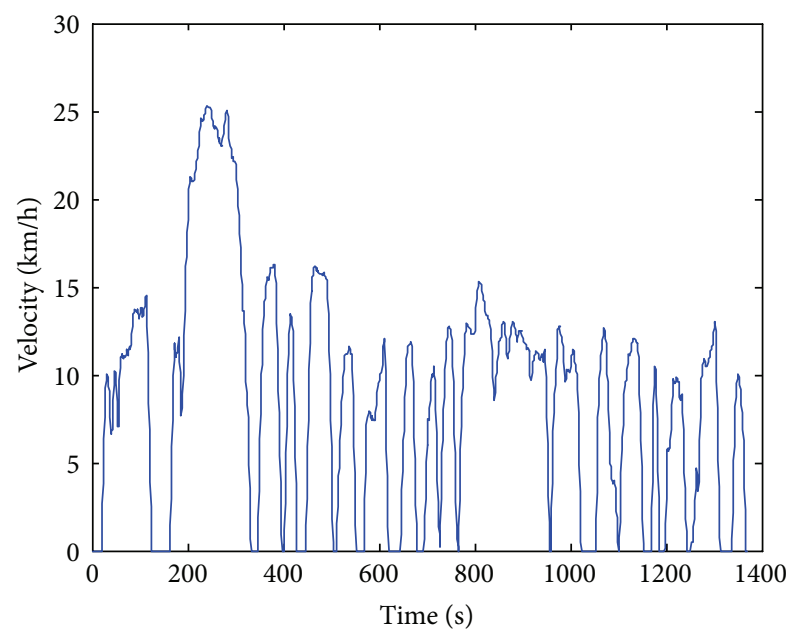

FIGURE 15: UDDS driving cycle.

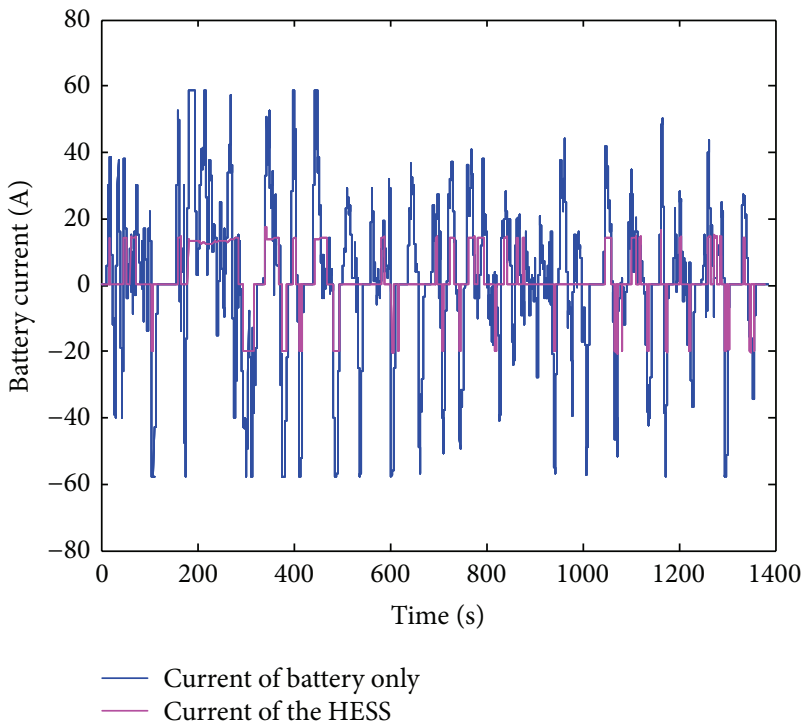

FIgURE 16: Comparison of the battery current curves.

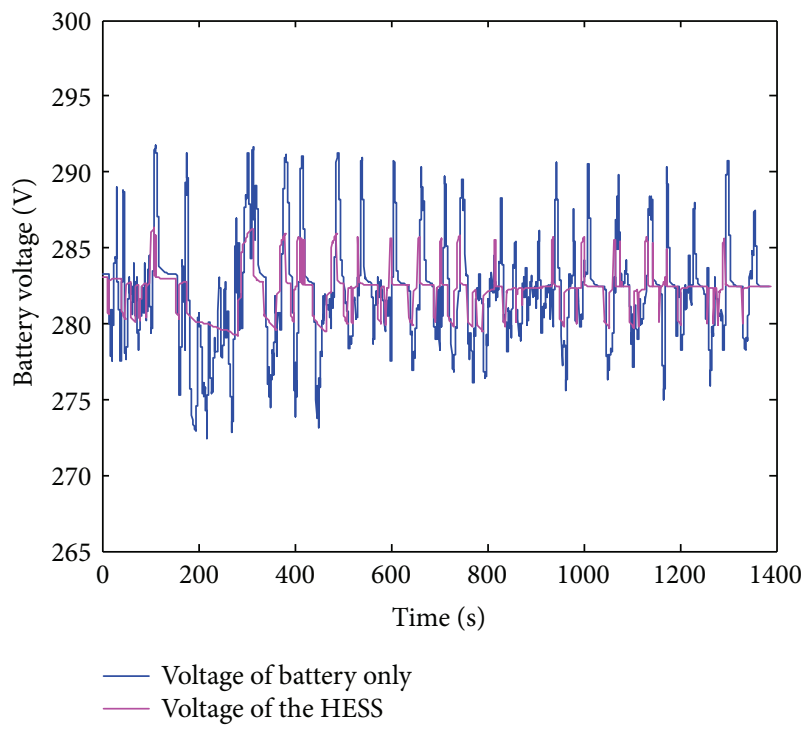

FIgURE 17: Comparison of the battery voltage curves.

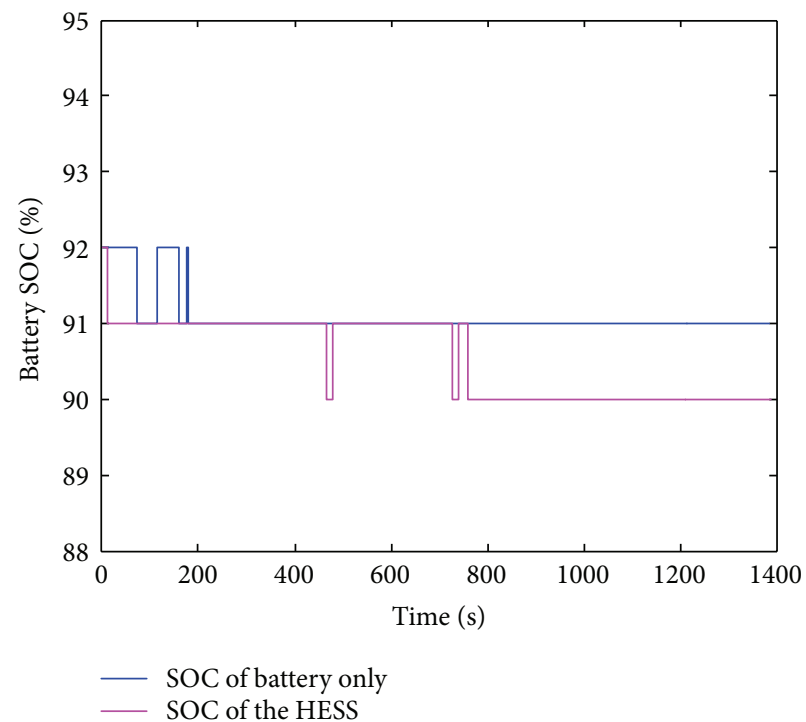

FIGURE 18: Comparison of the battery SOC curves.

of battery cells, a maximum $0.11 \mathrm{~V}$ voltage drop compared with a maximum $0.28 \mathrm{~V}$ voltage drop for battery only system is roughly estimated. Therefore, it is obvious that the battery system is operated in much smaller voltage fluctuation range and the potential battery cell balancing problem can be avoided to prevent individual cell voltages drift from time to time, which leads to rapid decreases of the total pack capacity, or even complete system failure.

The comparison of the battery SOC is shown in Figure 18. Since the supercapacitor pack absorbs the braking energy actively and efficiently and affords the additional peak power to meet the vehicle driving power requirement, the SOC of the battery pack is smoothed, which can be better found in Figure 25. By comparison, the benefit to electric vehicle range extension seems to be limited. This is because more braking 


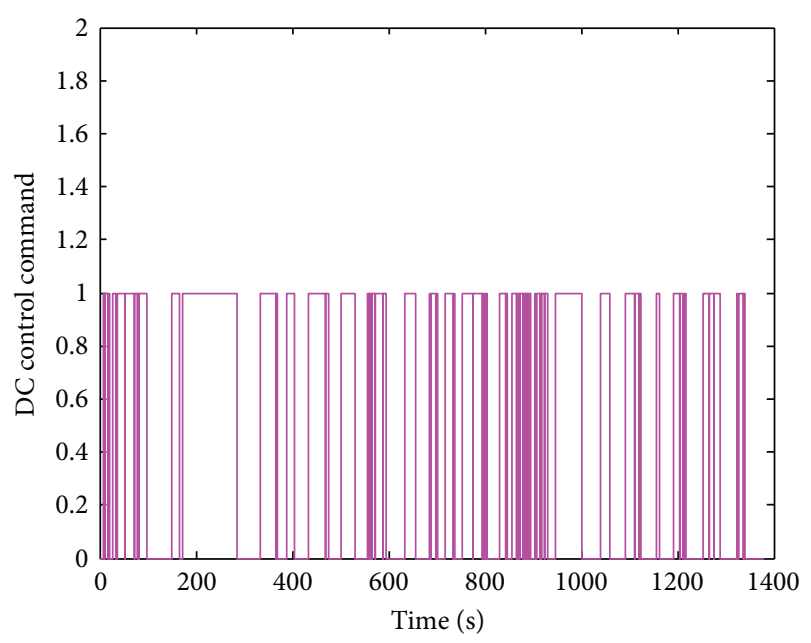

FIGURE 19: DC/DC converter control command.

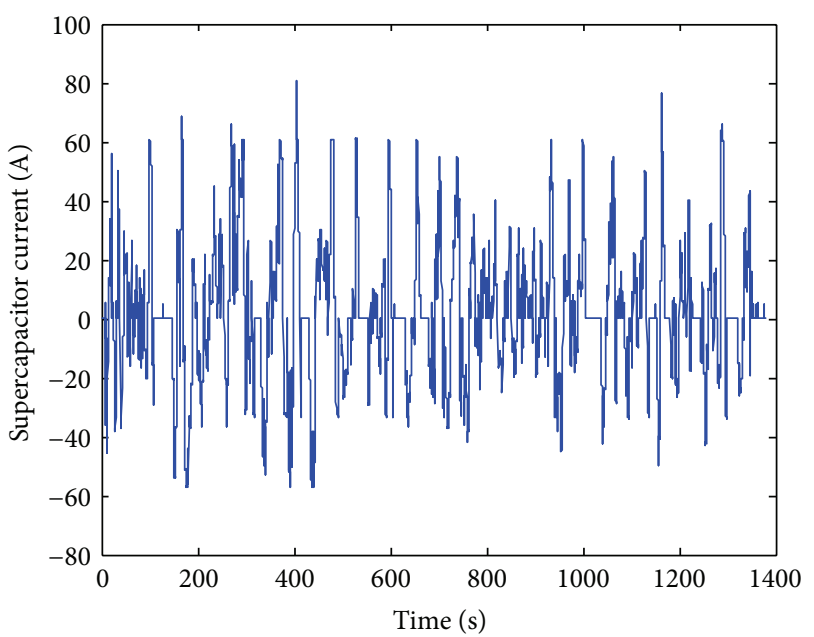

Figure 20: Supercapacitor current.

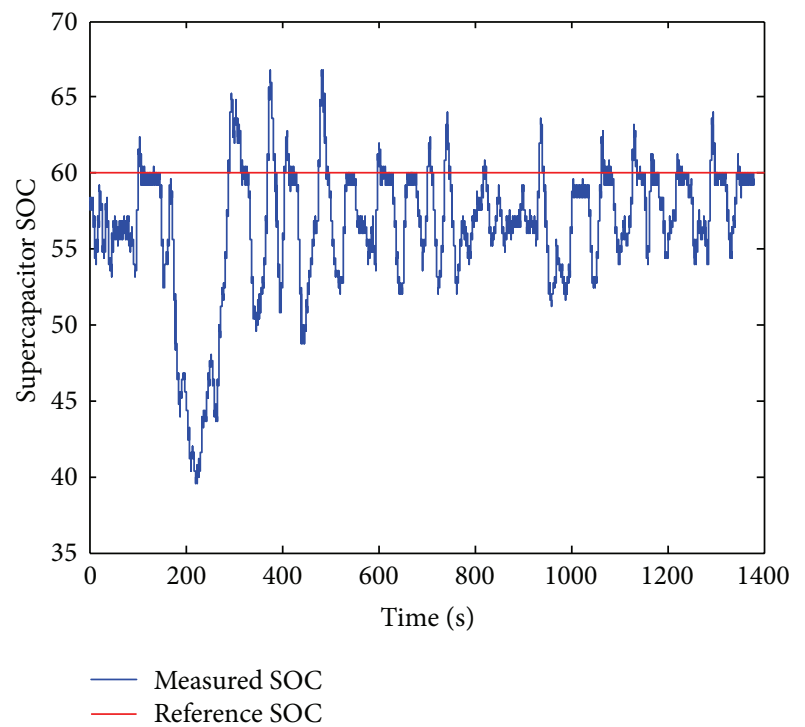

FIGURE 21: Supercapacitor SOC.
TABLE 2: Parameters of the battery pack.

\begin{tabular}{lc}
\hline Items & Specifications \\
\hline Nominal voltage & $280 \mathrm{~V}$ \\
Nominal capacity & $60 \mathrm{Ah}$ \\
Number of cells & 74 \\
Maximum continuous power & $30 \mathrm{~kW} / 13 \mathrm{~s}$ \\
Pack mass & $280 \mathrm{~kg} \pm 5 \%$ \\
Maximum charging temperature & $+45^{\circ} \mathrm{C}$ \\
Minimum charging temperature & $0^{\circ} \mathrm{C}$ \\
Maximum discharging temperature & $+40^{\circ} \mathrm{C}$ \\
Minimum discharging temperature & $-20^{\circ} \mathrm{C}$ \\
Maximum storage temperature & $+45^{\circ} \mathrm{C}$ \\
Minimum storage temperature & $-20^{\circ} \mathrm{C}$ \\
Lifetime & $25^{\circ} \mathrm{C}, \geq 1500$ times \\
Communication type & $\mathrm{CAN} 2.0 \mathrm{~B}, \mathrm{~J} 1939$ \\
Charging time & $1.5 \mathrm{hours}$ \\
Initial 50 V module resistance & $20 \mathrm{~m} \Omega$ \\
Shock & $\mathrm{SAE} \mathrm{J} 2464$ \\
\hline
\end{tabular}

TABLE 3: Parameters of the DC/DC converter.

\begin{tabular}{lc}
\hline Items & Specifications \\
\hline Boost voltage & $200-400 \mathrm{~V}$ \\
Buck voltage & $120-240 \mathrm{~V}$ \\
Rated power & $15 \mathrm{~kW}$ \\
Maximum buck current & $125 \mathrm{~A}$ \\
Maximum boost current & $75 \mathrm{~A}$ \\
Maximum operating temperature & $+60^{\circ} \mathrm{C}$ \\
Minimum operating temperature & $-20^{\circ} \mathrm{C}$ \\
Maximum storage temperature & $+70^{\circ} \mathrm{C}$ \\
Minimum storage temperature & $-30^{\circ} \mathrm{C}$ \\
Communication type & $\mathrm{CAN} 2.0 \mathrm{~B}, \mathrm{~J} 1939$ \\
Ripple coefficient & $\leq 1 \%$ \\
\hline
\end{tabular}

energy is absorbed by battery only system. These operations obviously decrease system efficiency and battery lifetime.

The current of the supercapacitor pack is described in Figure 20. Because of the fast dynamics and high system efficiency characteristic of the supercapacitor pack, the high frequency and peak current requirements are distributed to the supercapacitor pack. This can thus protect battery system from the high dynamics in the loads and increase the battery pack lifetime and system efficiency.

The SOC of the supercapacitor pack is described in Figure 21. It can be obviously observed that the developed control strategy can successfully maintain supercapacitor SOC within suitable variation range and achieve its final value ( $60 \%$ is designed as the final value). Consequently, the battery pack's working condition can be greatly optimized benefiting from the more frequent and effective participation of the supercapacitor in the load share operation. Besides, electric vehicle can be ensured to start a new cycle even if large loads are required given that the supercapacitor pack has enough energy and space to satisfy loads. 


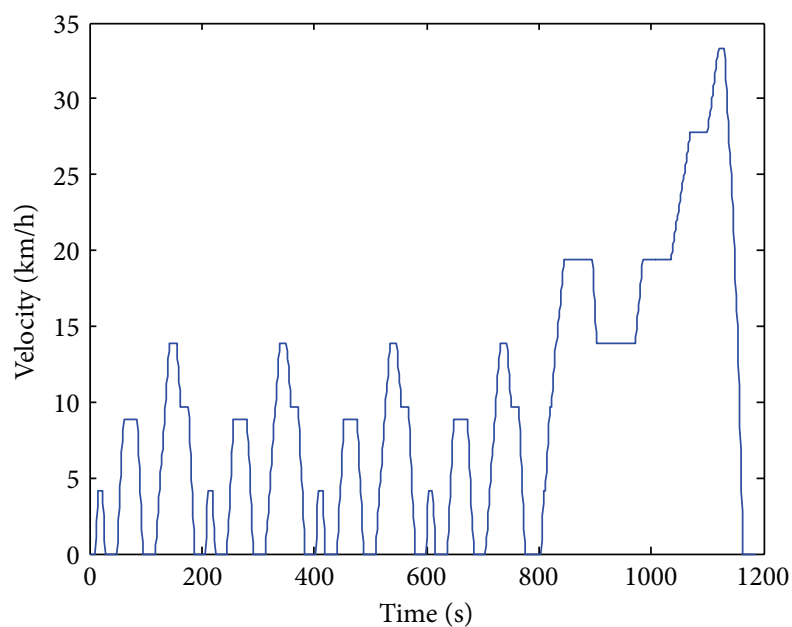

Figure 22: NEDC driving cycles.

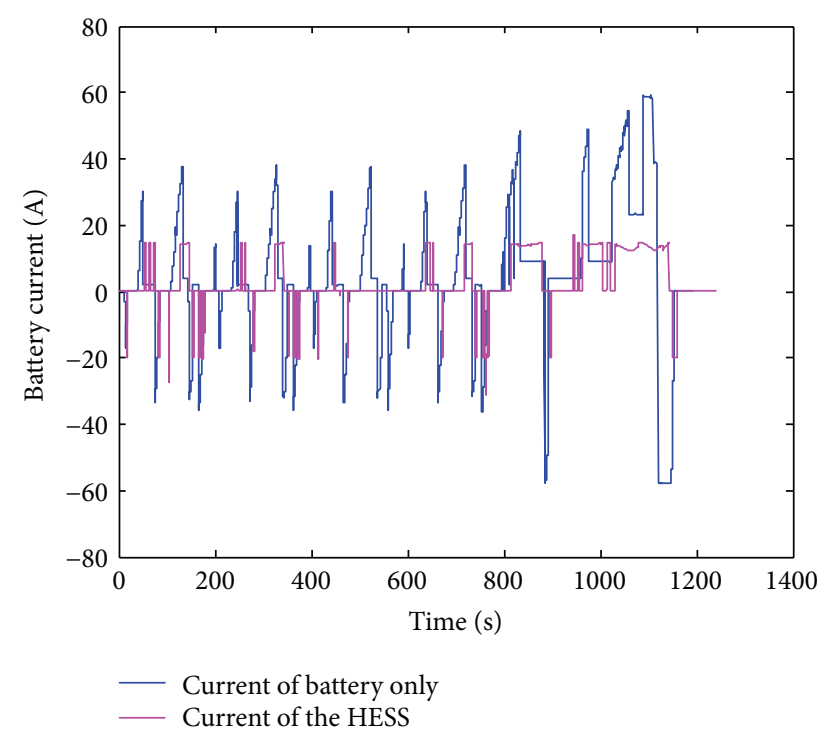

FIgURE 23: Comparison of the battery current curves.

Similar simulation was also carried out for the NEDC driving cycle, as shown in Figures 22-28. Again, in this case, the advantages of the proposed energy management control strategy proved to be effective in achieving battery lifetime and system efficiency.

5.2. Efficiency Analysis of the Hybrid System. In this subsection, the energy loss is analyzed to evaluate the effectiveness of the DC/DC converter used in the HESS. Since the energy efficiency has a big relevance with the resistances of the battery and supercapacitor packs and the efficiency of the $\mathrm{DC} / \mathrm{DC}$ converter, thus the resistance test for the battery and supercapacitor packs and the efficiency of the DC/DC converter test are firstly carried out. The results are plotted in Figures 29-31.

The energy loss comparisons of two semiactive topological structures described in Figures 3 and 4 and battery only system for UDDS driving cycle are shown in Figure 32. It can

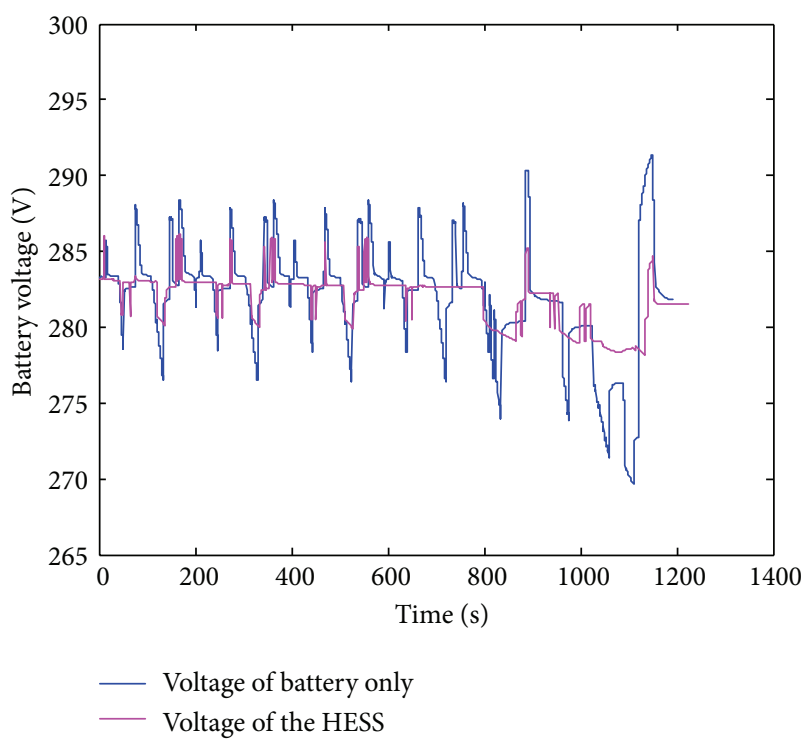

FIGURE 24: Comparison of the battery voltage curves.

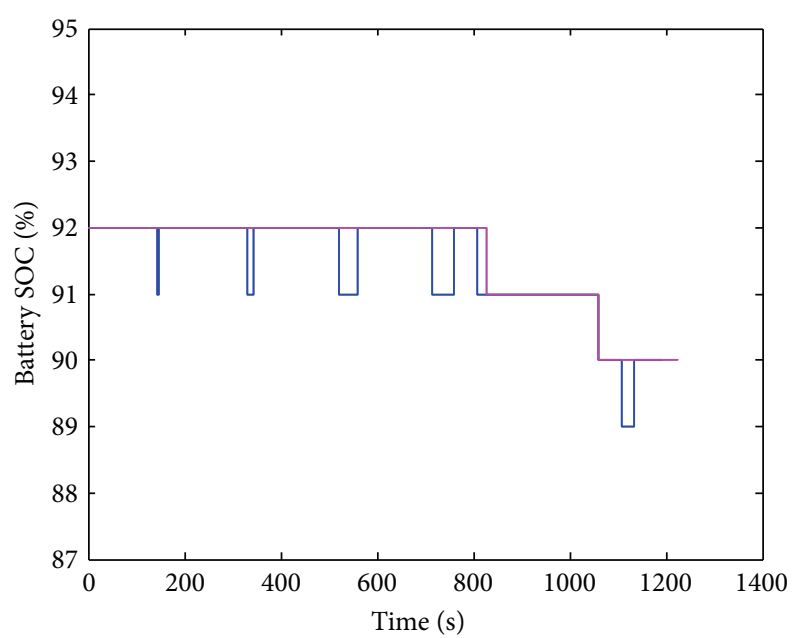

— SOC of battery only

— SOC of the HESS

FIGURE 25: Comparison of the battery SOC curves.

be observed that the energy loss of the semiactive topological structures described in Figure 4 is about $400 \mathrm{~kJ}$, and the energy loss in the semiactive topological structures described in Figure 3 is about $250 \mathrm{~kJ}$. Therefore, the energy efficiency of the semiactive topological structures described in Figure 3 is higher than that of the semiactive topological structures described in Figure 4. This is because the supercapacitor pack is adjusted by the DC/DC converter to satisfy the load current frequently, consequently resulting in more energy loss from the DC/DC converter. Therefore, the increased range largely depends on the energy efficiency of the DC/DC converter. To clarify the issue for future DC/DC converter development in the HESS, the energy losses of the components in two semiactive topological structures are described in Figures 33 and 34. It can be observed that the energy loss of the HESS is 


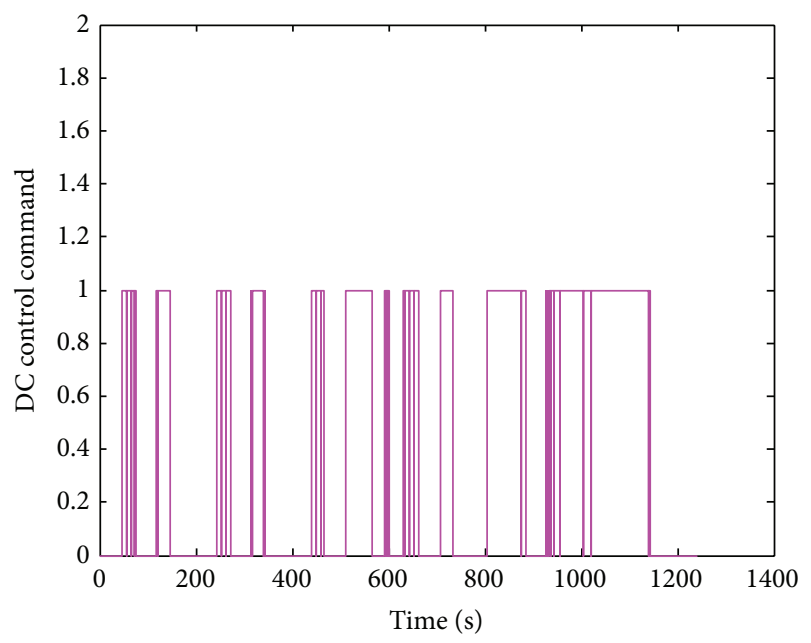

FiguRE 26: DC/DC converter control command.

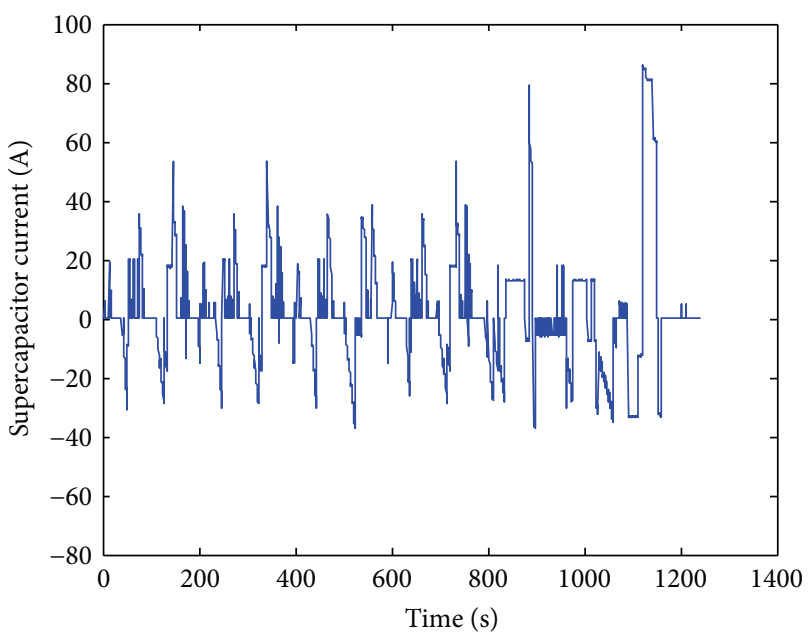

FIgURE 27: Supercapacitor current.

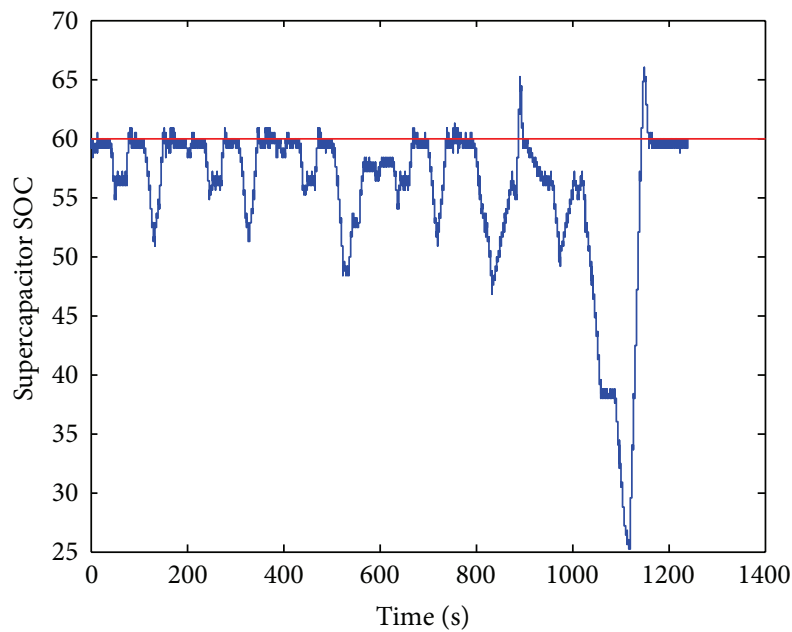

- Measured SOC

FIGURE 28: Supercapacitor SOC.

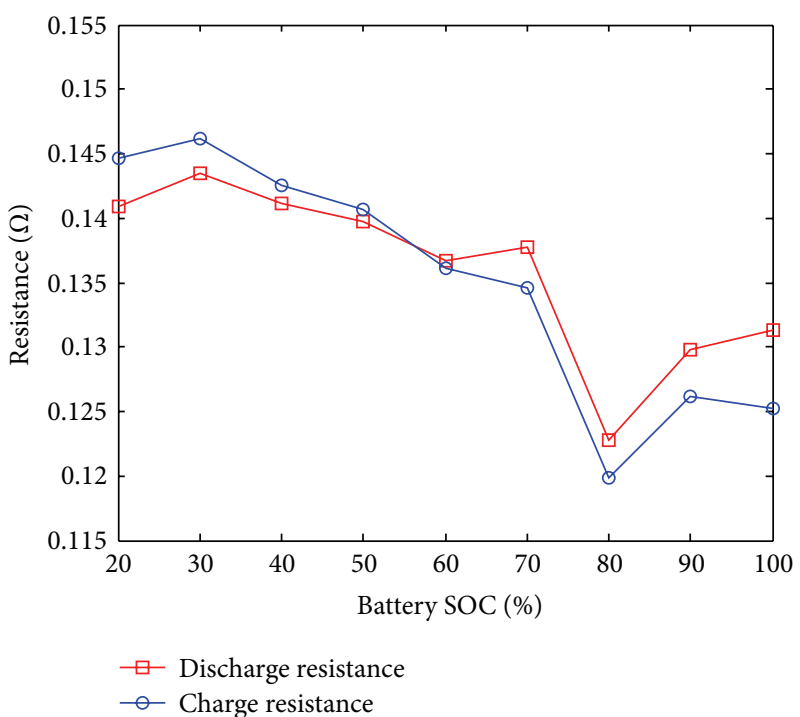

FIGURE 29: Charging/discharging internal resistances of the battery pack.

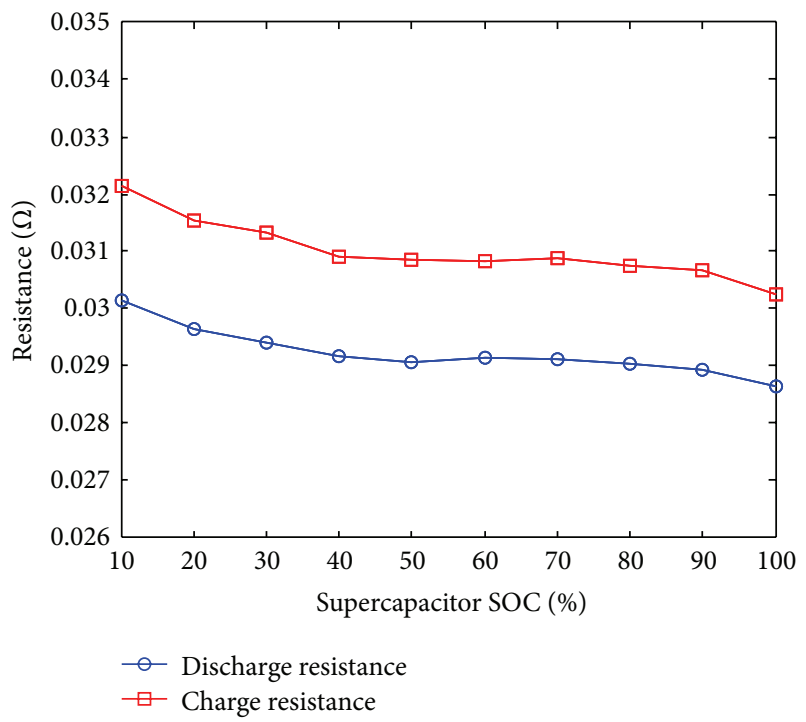

FIGURE 30: Charging/discharging internal resistances of the supercapacitor pack.

mainly from the energy loss of the DC/DC converter. Besides, the energy loss of the battery only system is higher than the total energy loss of the battery and supercapacitor pack in the HESS; it is thus suggested that the efficiency of the DC/DC converter needs to be increased to one certain limit value, which can effectively compensate for the energy loss difference between the HESS and the battery only system. Similar results can be found in Figures 35-37. According to the experiment results and theoretical analysis, based on the developed energy management strategy and the semiactive topological structure described in Figure 3, the DC/DC converter at least has $97 \%$ conversion efficiency to make the HESS energy effective compared to the battery only system. 


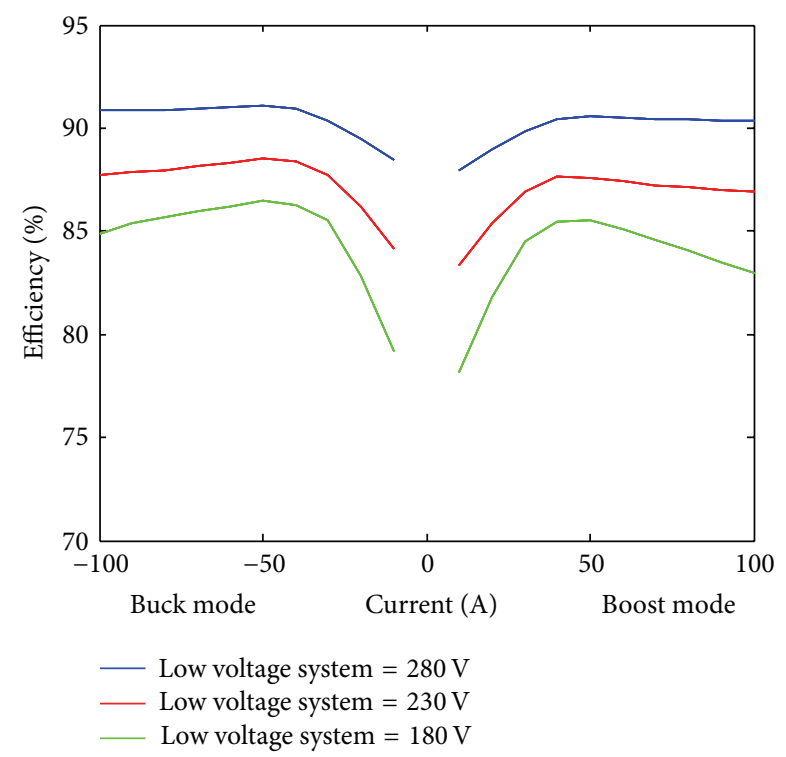

Figure 31: Efficiency map of the DC/DC converter.

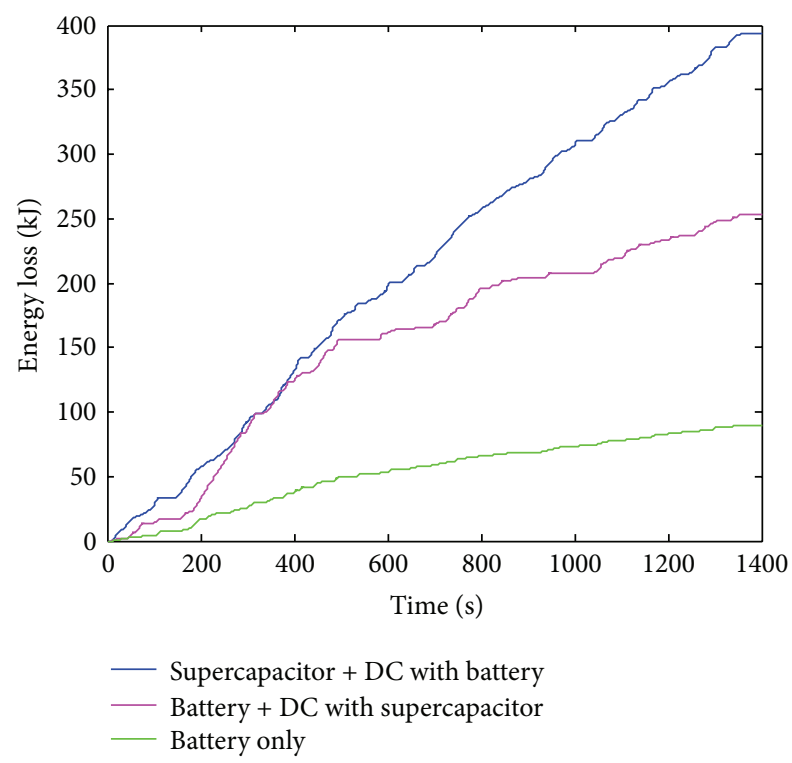

FIGURE 32: Energy loss comparisons of two semiactive topological structures and battery only system for UDDS driving cycle.

5.3. Cost Analysis of the Hybrid System. In this section, the cost model of hybrid system is established. The model mainly consists of battery life cost and system electricity cost.

The battery life model is developed in order to analyze the impact of terrain inaccuracy on battery life. Since supercapacitor has much longer life cycle compared to that of battery, it is assumed that the supercapacitor has no degradation during the battery lifetime. The model on battery capacity dynamic degradation adopted in this research is a semiempirical life model [33]. The model includes four parameters, namely, time, temperature, depth of charge, and discharge rate. The

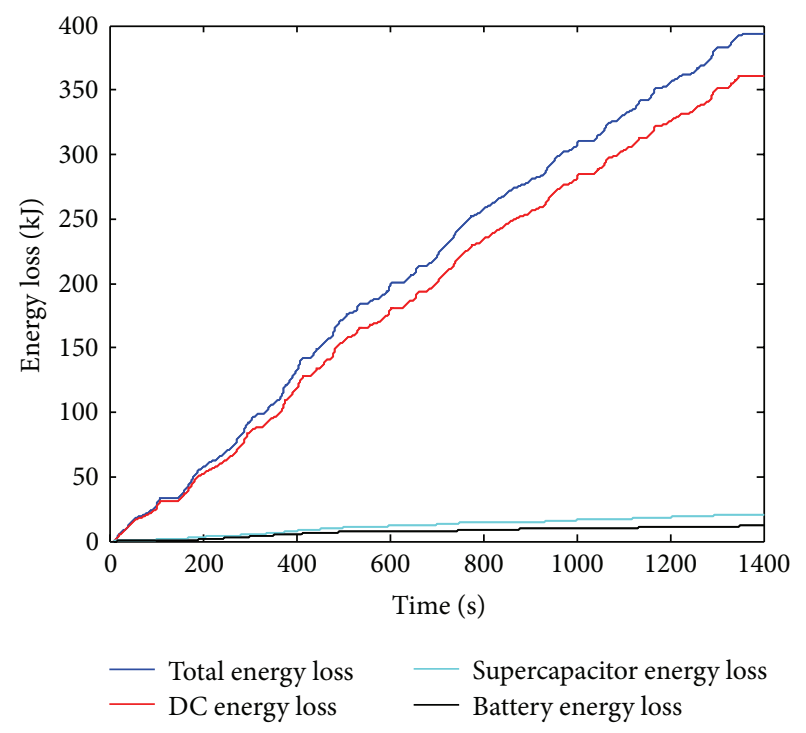

Figure 33: Energy loss of the semiactive topological structure described in Figure 4 for UDDS driving cycle.

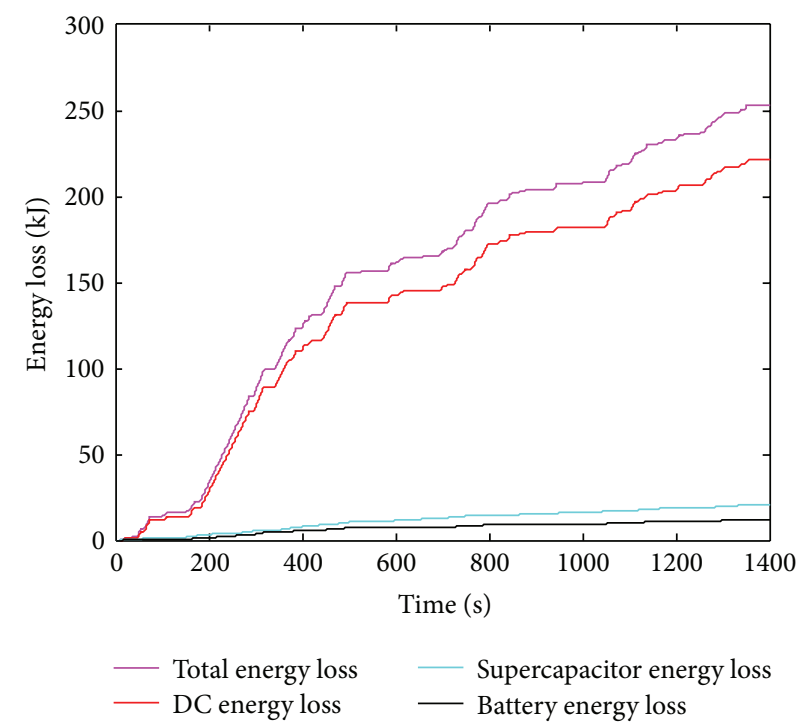

Figure 34: Energy loss of the semiactive topological structure described in Figure 3 for UDDS driving cycle.

variations of these parameters will influence battery lifetime directly. The formula of battery life model is given by

$$
\mathrm{Q}_{\text {loss }}=B \cdot e^{-\left(\left(E_{a}+B \cdot C_{\text {rate }}\right) /\left(R \cdot T_{\text {bat }}\right)\right)}\left(A_{h}\right)^{z},
$$

where $Q_{\text {loss }}$ is the battery capacity loss which ranges from 0 to $1 . B$ is the preexponential factor, $E_{a}$ is the activation energy $\left(\mathrm{J} \mathrm{mol}^{-1}\right), R$ is the gas constant $\left(\mathrm{J}\left(\mathrm{mol}^{-1} \mathrm{k}\right)^{-1}\right), T$ is the battery absolute temperature $(\mathrm{K}), A_{h}$ is the Ah-throughput, which is expressed as $A_{h}, z$ is the power law factor, $C_{\text {rate }}$ is the battery discharge rate, and $B$ is the compensation factor of $C_{\text {rate }}$. The original formula is developed based on $\mathrm{LiFePO}_{4}$ battery test results. For the consideration battery studied in this paper, a correction coefficient can be considered to predict battery 


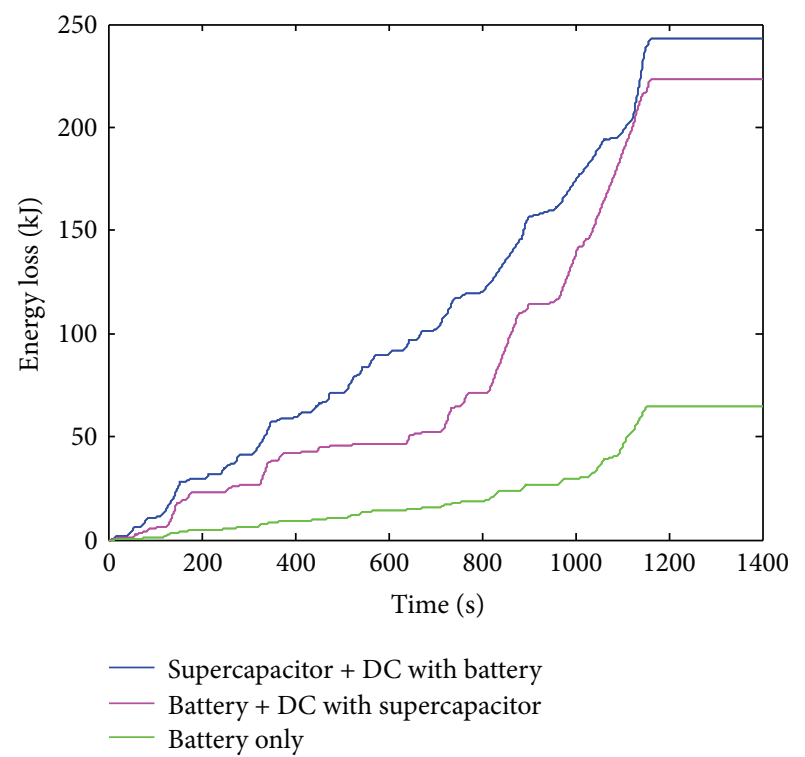

FIGURE 35: Energy loss comparisons of two semiactive topological structures and battery only system for NEDC driving cycle.

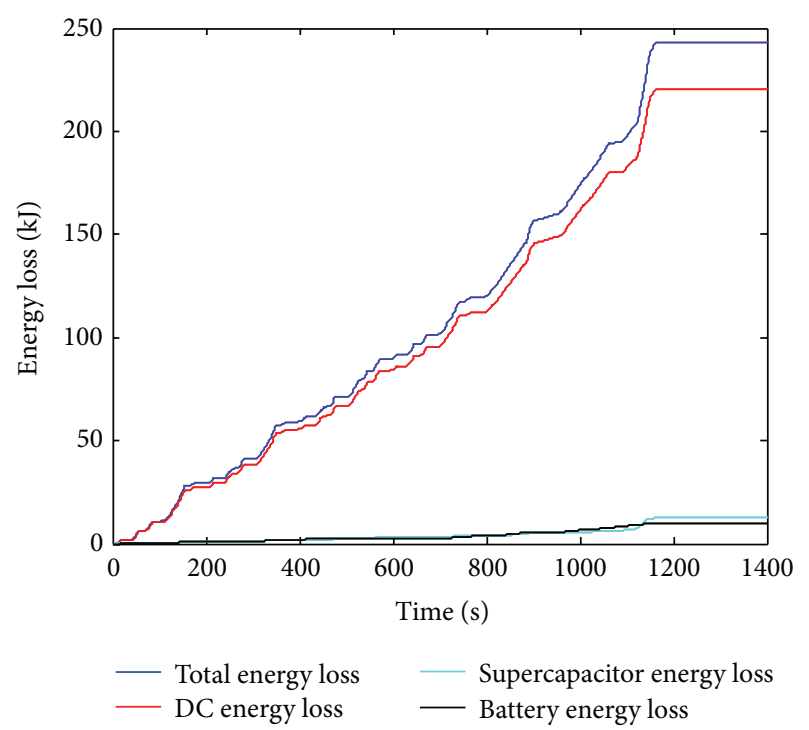

FIGURE 36: Energy loss of the semiactive topological structure described in Figure 4 for NEDC driving cycle.

lifetime more accurately. Then the formula can be rewritten as

$$
Q_{\text {loss }}=\beta \cdot B \cdot e^{-\left(\left(E_{a}+B \cdot C_{\text {rate }}\right) /\left(R \cdot T_{\text {bat }}\right)\right)}\left(A_{h}\right)^{z},
$$

where $\beta$ is the correction coefficient: $\beta=1.7 \times 10^{-4}$. Other parameters used in this formula are listed in Table 4 . The Ahthroughput $A_{h}$ is defined as

$$
A_{h}=\frac{1}{3600} \int_{t_{0}}^{t_{f}}\left|I_{\text {bat }}\right| d t
$$

where $t_{0}$ is the initial time of a driving cycle and $t_{f}$ is the final time of a driving cycle.

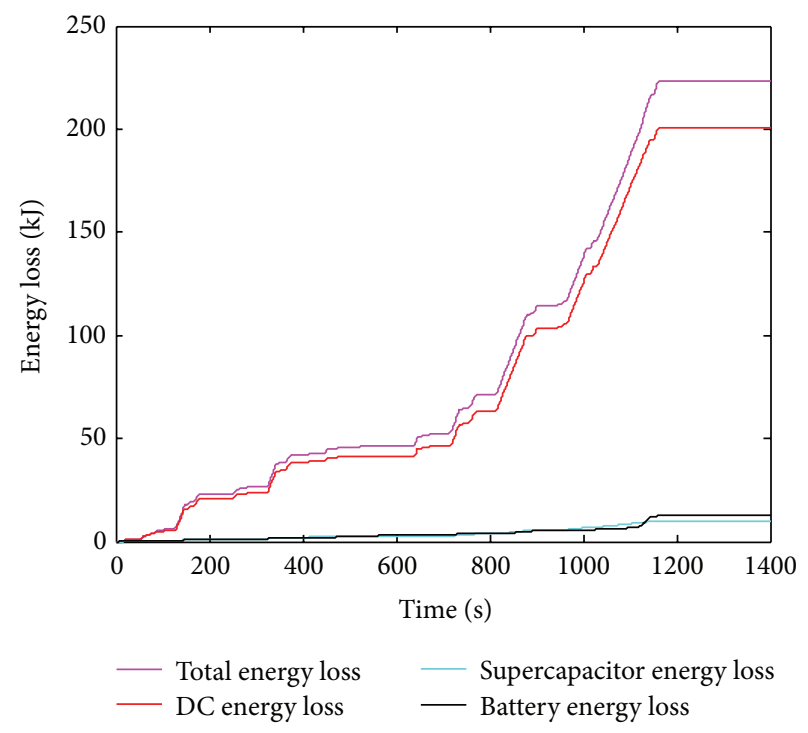

Figure 37: Energy loss of the semiactive topological structure described in Figure 3 for NEDC driving cycle.

TABle 4: Parameters of battery life model.

\begin{tabular}{lc}
\hline Item & Value \\
\hline$B$ & 30330 \\
$E_{a}$ & 31700 \\
$R$ & 8.314 \\
$B$ & 370.3 \\
$z$ & 0.55 \\
\hline
\end{tabular}

The problem of the battery life is formulated as battery life cost. The cost of energy storage system is assumed to be $1600 \mathrm{USD} / \mathrm{kWh}$ for the battery system and $15000 \mathrm{USD} / \mathrm{kWh}$ for the supercapacitor. The electricity cost is assumed to be $0.1 \mathrm{USD} / \mathrm{kWh}$ according to the report of the US Energy Information Administration. Since it is assumed that the supercapacitor has no degradation during battery lifetime, only battery degradation cost is considered in two hybrid energy storage systems with semiactive topology. In general, battery can hardly be used when its capacity is reduced to $80 \%$ of its initial value. Therefore, the cost description of the battery life and the electricity can be given by

$$
\begin{aligned}
& \text { Cost }_{\text {bat,loss }}(t) \\
& =24.768 \\
& \quad \times \int_{0}^{t} \frac{\left|I_{\text {bat }}\right|}{3600} d t \exp -\left(\frac{31700-370.3 C_{\text {rate }}}{8.314 T_{\text {bat }}}\right), \\
& \text { Cost }_{\text {ele }}(t)=\frac{0.1}{3600} \int_{0}^{T}\left[P_{\text {SC }}(t)+P_{\text {bat }}(t)\right] .
\end{aligned}
$$

Note that the electricity cost can be influenced by the resistance losses for both battery and supercapacitor and efficiency loss for the DC/DC converter. In this work, the resistances of battery and supercapacitor and the efficiency of DC converter are simplified as a fixed value. Thus the total 


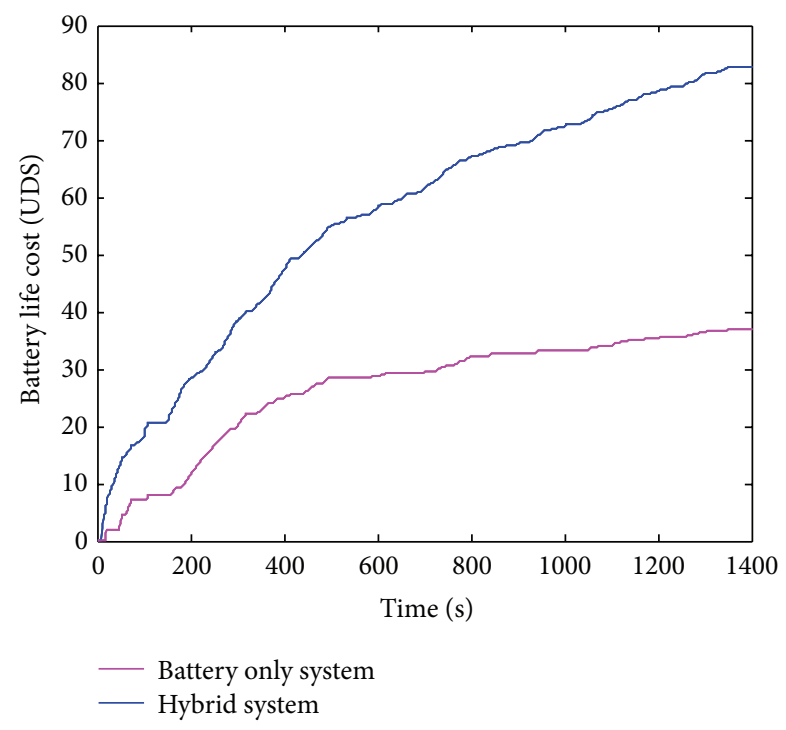

FIGURE 38: Comparison of the battery life cost based on UDDS driving cycle.

cost comprising battery life and electricity cost can be written as

$$
\operatorname{Cost}(t)=\operatorname{Cost}_{\text {life }}(t)+\text { Cost }_{\text {ele }}(t) \text {. }
$$

The comparison results of the battery life cost and the system electricity cost based on UDDS driving cycle and NEDC driving cycle are given in Figures 38-41. From Figure 38, it has been demonstrated clearly that hybrid system has an absolute advantage in improving battery life compared with the battery only system. However, the system electricity cost is increased because of the energy loss of the supercapacitor and the DC/DC converter. By comparison, the battery life cost is obviously higher than the system electricity cost. Therefore, to pursue the maximum benefit of the hybrid system, the battery life cost should be considered as the main factor in the total cost. In the future, when the battery is very cheap, the system electricity cost may be dominant in the total cost. By then, an appropriate balance between the battery life cost and the system electricity cost need be considered. From Figures 40 and 41, similar conclusions can be obtained.

\section{Conclusion}

In this paper, a rule based energy management system is developed for the battery and supercapacitor HESS. The objective of the proposed system is to focus on exploiting the supercapacitor characteristics and on increasing the battery lifetime and system efficiency. Two controllers of the DC/DC converter are designed and integrated to achieve this purpose. Firstly, a current controller is designed to realize load current distribution between battery and supercapacitor. Then a voltage controller is designed to ensure the supercapacitor SOC fluctuate within a preset reasonable variation range.

Experiment results have shown that the system enables the battery to share the low frequency load current, which

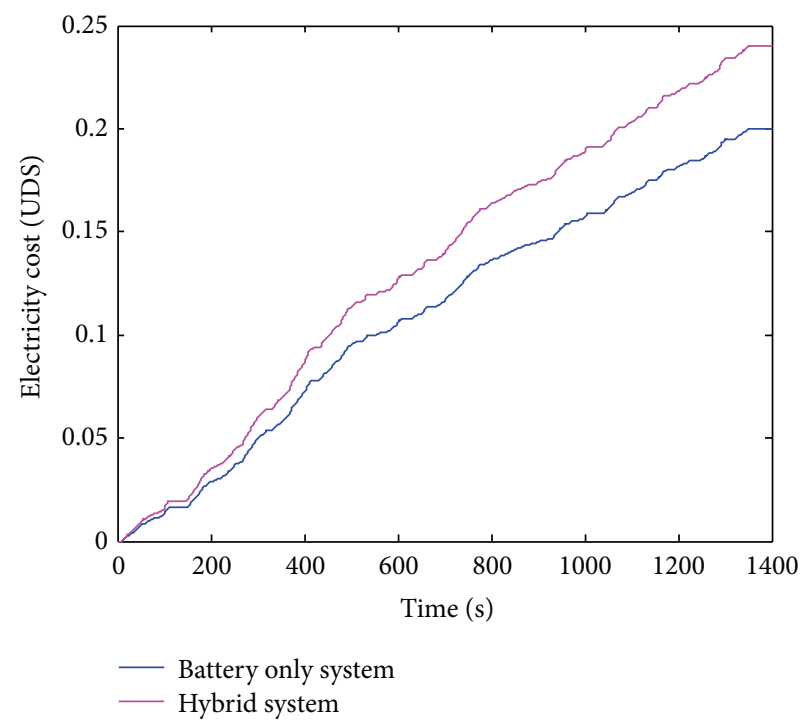

FIGURE 39: Comparison of the electricity cost based on UDDS driving cycle.

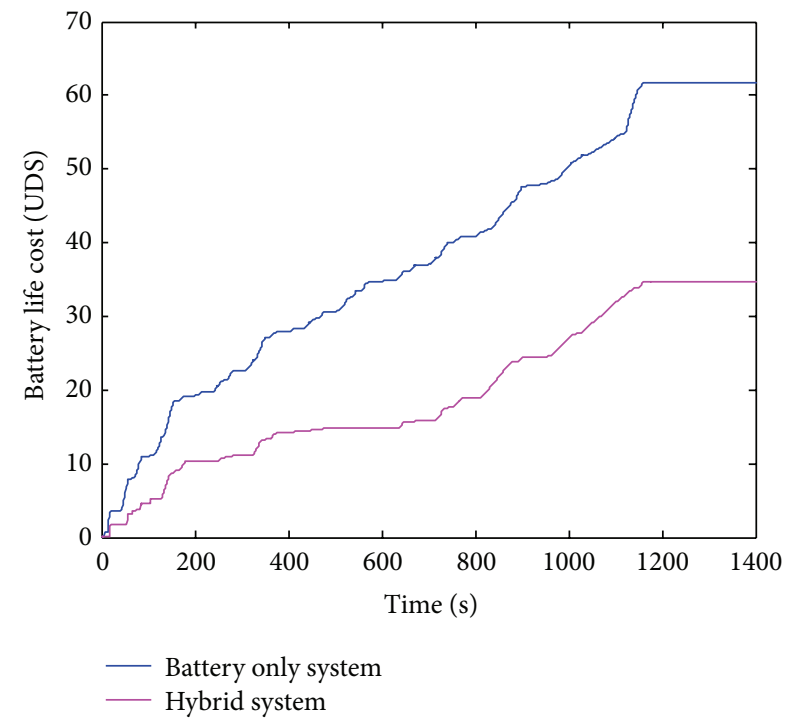

FIgURE 40: Comparison of the battery life cost based on NEDC driving cycle.

would be very helpful to increase battery lifetime. Correspondingly, the high frequency load current is distributed to the supercapacitor pack. Efficiency analysis has revealed that the semiactive topological structure described in Figure 3 has a higher energy efficiency compared with the semiactive topological structure described in Figure 4. The increased range depends on the energy efficiency of the DC/DC converter largely. Besides, the DC/DC converter at least has 97\% conversion efficiency to make the HESS energy effective compared to the battery only system. The preliminary cost analysis of hybrid system has demonstrated that hybrid system can increase battery lifetime obviously compared with battery only system. At the same time, the analysis also highlights that an appropriate balance between the battery life 


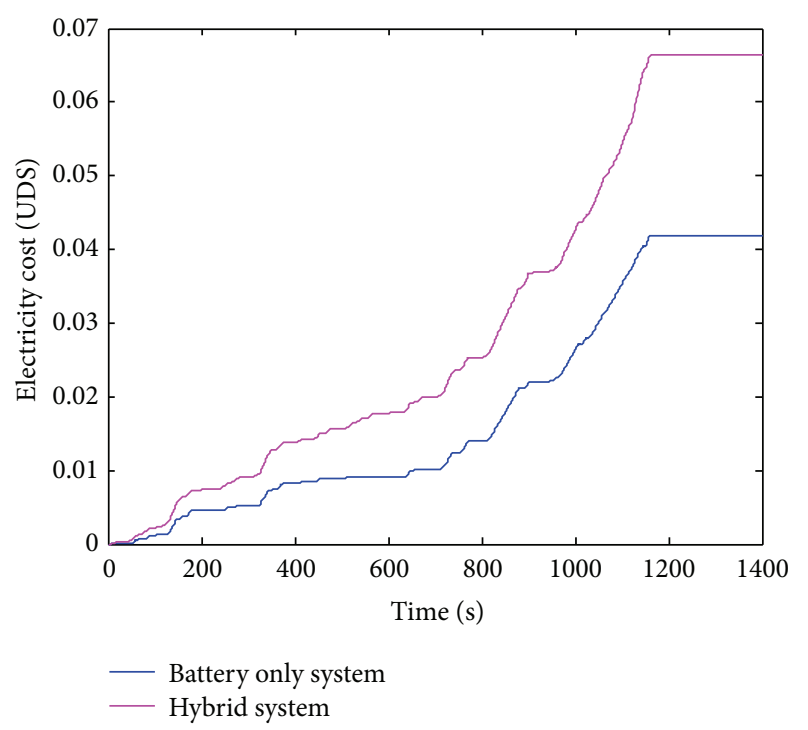

Figure 41: Comparison of the electricity cost based on NEDC driving cycle.

cost and the system electricity cost is necessary to pursue the maximum benefit of the hybrid system in the future.

\section{Competing Interests}

The authors declare that there are no competing interests regarding the publication of this paper.

\section{Acknowledgments}

The authors wish to acknowledge the support of National Science Foundation of China under Grant U1564211.

\section{References}

[1] S. M. Lukic, J. Cao, R. C. Bansal, F. Rodriguez, and A. Emadi, "Energy storage systems for automotive applications," IEEE Transactions on Industrial Electronics, vol. 55, no. 6, pp. 22582267, 2008.

[2] H.-W. He, R. Xiong, and Y.-H. Chang, "Dynamic modeling and simulation on a hybrid power system for electric vehicle applications," Energies, vol. 3, no. 11, pp. 1821-1830, 2010.

[3] R. F. Nelson, "Power requirements for batteries in hybrid electric vehicles," Journal of Power Sources, vol. 91, no. 1, pp. 226, 2000.

[4] K. T. Chau and C. C. Chan, "Emerging energy-efficient technologies for hybrid electric vehicles," Proceedings of the IEEE, vol. 95, no. 4, pp. 821-835, 2007.

[5] H. Rahimi-Eichi, U. Ojha, F. Baronti, and M.-Y. Chow, "Battery management system: an overview of its application in the smart grid and electric vehicles," IEEE Industrial Electronics Magazine, vol. 7, no. 2, pp. 4-16, 2013.

[6] A. Khaligh and Z. Li, "Battery, ultracapacitor, fuel cell, and hybrid energy storage systems for electric, hybrid electric, fuel cell, and plug-in hybrid electric vehicles: state of the art," IEEE Transactions on Vehicular Technology, vol. 59, no. 6, pp. 28062814, 2010.
[7] S. F. Tie and C. W. Tan, "A review of energy sources and energy management system in electric vehicles," Renewable and Sustainable Energy Reviews, vol. 20, pp. 82-102, 2013.

[8] G. Ren, G. Ma, and N. Cong, "Review of electrical energy storage system for vehicular applications," Renewable and Sustainable Energy Reviews, vol. 41, pp. 225-236, 2015.

[9] S. Pay and Y. Baghzouz, "Effectiveness of battery-supercapacitor combination in electric vehicles," in Proceedings of the IEEE Bologna PowerTech Conference, pp. 728-733, June 2003.

[10] R. M. Schupbach and J. C. Balda, "The role of ultracapacitors in an energy storage unit for vehicle power management," in Proceedings of the IEEE Vehicle Technology Conference, pp. 32363240, 2003.

[11] M. Ortúzar, J. Moreno, and J. Dixon, "Ultracapacitor-based auxiliary energy system for an electric vehicle: implementation and evaluation," IEEE Transactions on Industrial Electronics, vol. 54, no. 4, pp. 2147-2156, 2007.

[12] G. Guidi, T. M. Undeland, and Y. Hori, "Effectiveness of supercapacitors as power-assist in pure EV using a sodiumnickel chloride battery as main energy storage," in Proceedings of the 24th International Battery, Hybrid and Fuel Cell Electric Vehicle Symposium and Exhibition, pp. 2190-2198, May 2009.

[13] L. Gao, R. A. Dougal, and S. Liu, "Power enhancement of an actively controlled battery/ultracapacitor hybrid," IEEE Transactions on Power Electronics, vol. 20, no. 1, pp. 236-243, 2005.

[14] R. Carter, A. Cruden, and P. J. Hall, "Optimizing for efficiency or battery life in a battery/supercapacitor electric vehicle," IEEE Transactions on Vehicular Technology, vol. 61, no. 4, pp. 15261533, 2012.

[15] P. Ruetschi, "Aging mechanisms and service life of lead-acid batteries," Journal of Power Sources, vol. 127, no. 1-2, pp. 33-44, 2004.

[16] P. Lailler, F. Zaninotto, S. Nivet et al., "Study of the softening of the positive active-mass in valve-regulated lead-acid batteries for electric-vehicle applications," Journal of Power Sources, vol. 78, no. 1, pp. 204-213, 1999.

[17] N. Omar, M. Daowd, O. Hegazy, P. V. D. Bossche, T. Coosemans, and J. V. Mierlo, "Electrical double-layer capacitors in hybrid topologies-assessment and evaluation of their performance," Energies, vol. 5, no. 11, pp. 4533-4568, 2012.

[18] F. Ju, Q. Zhang, W. Deng, and J. Li, "Review of structures and control of battery-supercapacitor hybrid energy storage system for electric vehicles," in Proceedings of the IEEE International Conference on Automation Science and Engineering (CASE '14), pp. 143-148, IEEE, Taipei, Taiwan, August 2014.

[19] A. Kuperman and I. Aharon, "Battery-ultracapacitor hybrids for pulsed current loads: a review," Renewable and Sustainable Energy Reviews, vol. 15, no. 2, pp. 981-992, 2011.

[20] O. C. Onar and A. Khaligh, "A novel integrated magnetic structure based DC/DC converter for hybrid battery/ultracapacitor energy storage systems," IEEE Transactions on Smart Grid, vol. 3, no. 1, pp. 296-307, 2012.

[21] A. C. Baisden and A. Emadi, "ADVISOR-based model of a battery and an ultra-capacitor energy source for hybrid electric vehicles," IEEE Transactions on Vehicular Technology, vol. 53, no. 1, pp. 199-205, 2004.

[22] J. P. Trovão, P. G. Pereirinha, H. M. Jorge, and C. H. Antunes, "A multi-level energy management system for multi-source electric vehicles-an integrated rule-based meta-heuristic approach," Applied Energy, vol. 105, pp. 304-318, 2013. 
[23] Z. Chenghui, S. Qingsheng, C. Naxin, and L. Wuhua, "Particle swarm optimization for energy management fuzzy controller design in dual-source electric vehicle," in Proceedings of the IEEE 38th Annual Power Electronics Specialists Conference (PESC '07), pp. 1405-1410, June 2007.

[24] Y. Ates, O. Erdinc, M. Uzunoglu, and B. Vural, "Energy management of an FC/UC hybrid vehicular power system using a combined neural network-wavelet transform based strategy," International Journal of Hydrogen Energy, vol. 35, no. 2, pp. 774783, 2010.

[25] M.-E. Choi, S.-W. Kim, and S.-W. Seo, "Energy management optimization in a battery/supercapacitor hybrid energy storage system," IEEE Transactions on Smart Grid, vol. 3, no. 1, pp. 463472, 2012.

[26] B. Hredzak, V. G. Agelidis, and M. Jang, "A model predictive control system for a hybrid battery-ultracapacitor power source," IEEE Transactions on Power Electronics, vol. 29, no. 3, pp. 1469-1479, 2014.

[27] X. Zhang, C. C. Mi, A. Masrur, and D. Daniszewski, "Wavelettransform-based power management of hybrid vehicles with multiple on-board energy sources including fuel cell, battery and ultracapacitor," Journal of Power Sources, vol. 185, no. 2, pp. 1533-1543, 2008.

[28] Y. Kim, T.-K. Lee, and Z. Filipi, "Frequency domain power distribution strategy for series hybrid electric vehicles," $S A E$ International Journal of Alternative Powertrains, vol. 1, no. 1, pp. 208-218, 2012.

[29] W. Gao, "Performance comparison of a fuel cell-battery hybrid powertrain and a fuel cell-ultracapacitor hybrid powertrain," IEEE Transactions on Vehicular Technology, vol. 54, no. 3, pp. 846-855, 2005.

[30] J. P. Zheng, T. R. Jow, and M. S. Ding, "Hybrid power sources for pulsed current applications," IEEE Transactions on Aerospace and Electronic Systems, vol. 37, no. 1, pp. 288-292, 2001.

[31] P. Thounthong and S. Rael, "The benefits of hybridization," IEEE Industrial Electronics Magazine, vol. 6, pp. 69-76, 2008.

[32] A. Khaligh and Z. Li, "Battery, ultracapacitor, fuel cell, and hybrid energy storage systems for electric, hybrid electric, fuel cell, and plug-in hybrid electric vehicles: State of the art," IEEE Transactions on Vehicular Technology, vol. 59, no. 6, pp. 28062814, 2010.

[33] J. Wang, P. Liu, J. Hicks-Garner et al., "Cycle-life model for graphite- $\mathrm{LiFePO}_{4}$ cells," Journal of Power Sources, vol. 196, no. 8, pp. 3942-3948, 2011. 


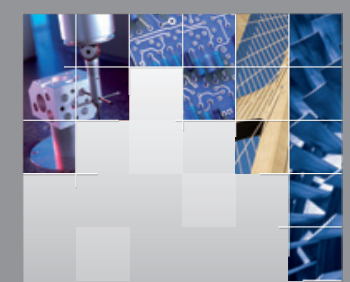

\section{Enfincering}
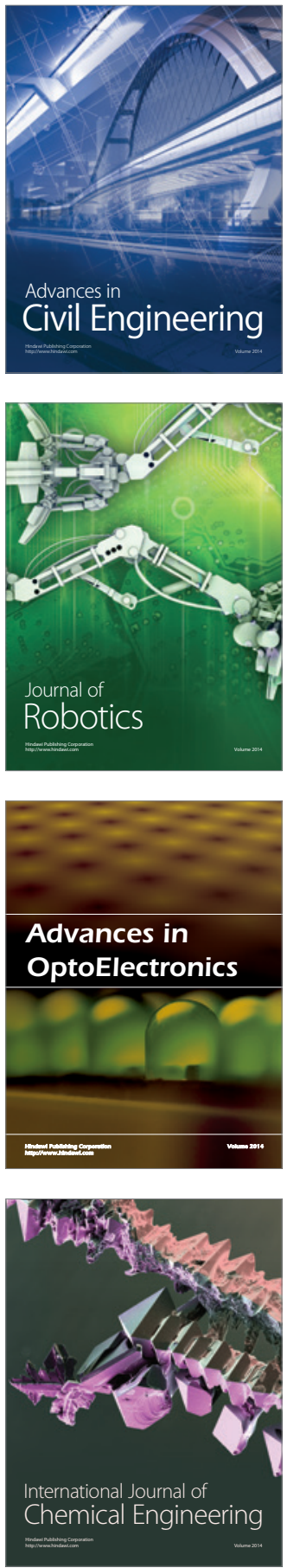

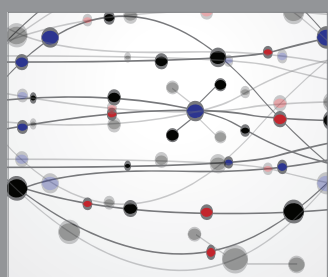

The Scientific World Journal

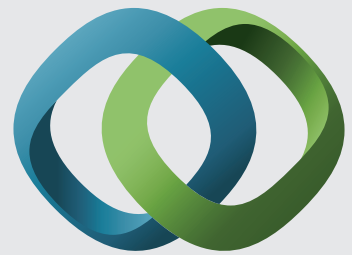

\section{Hindawi}

Submit your manuscripts at

http://www.hindawi.com
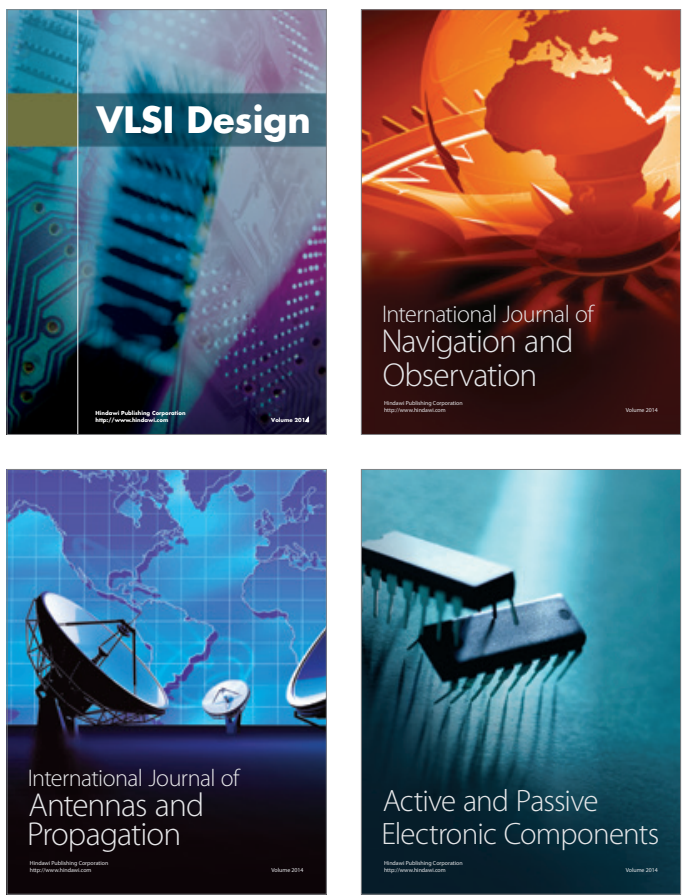
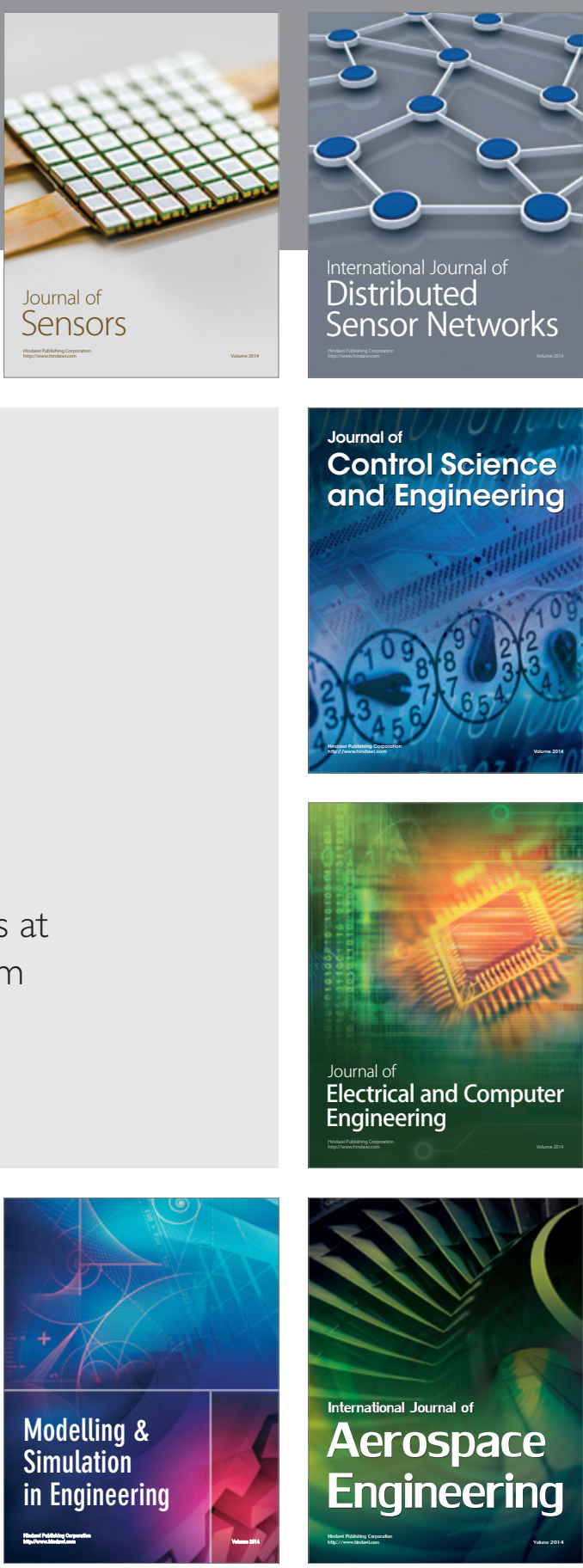

International Journal of

Distributed

Sensor Networks

Journal of

Control Science

and Engineering
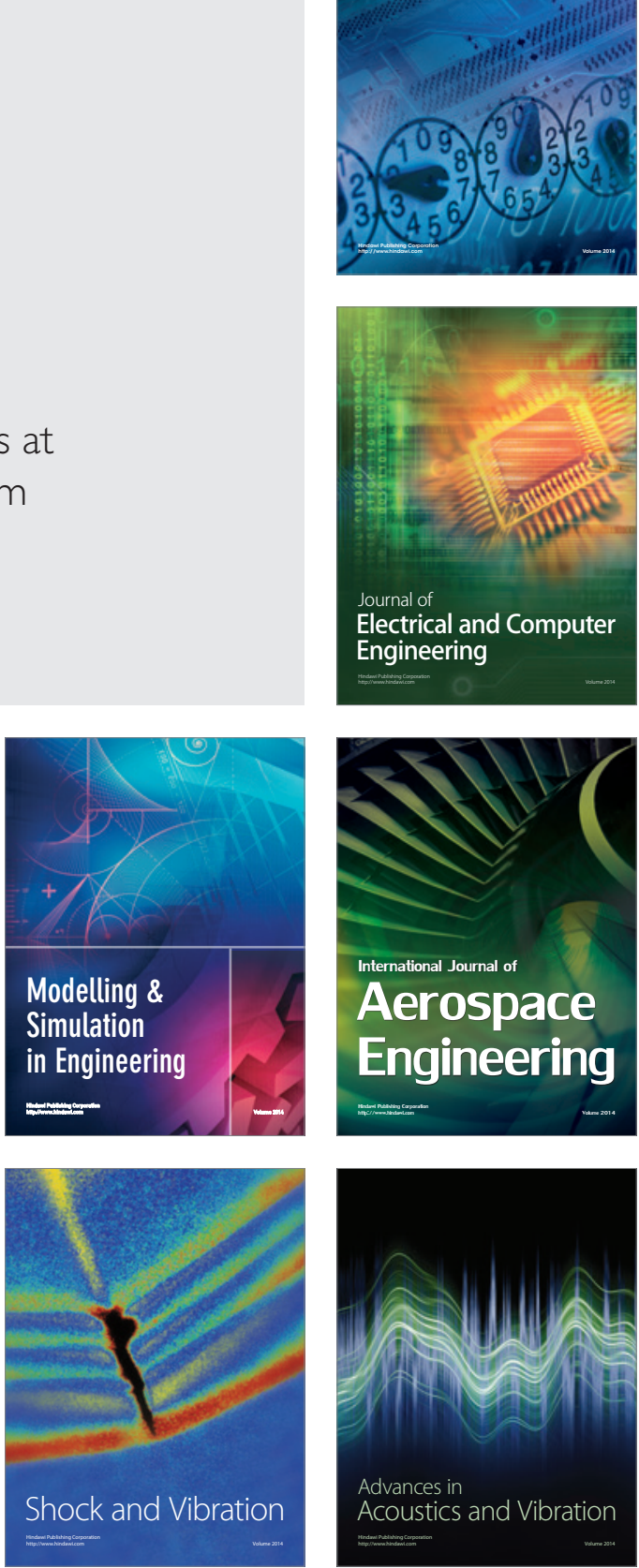